Running Head: SMARTPHONES \& RELATIONSHIPS

Smartphones and Close Relationships: The Case for an Evolutionary Mismatch

$$
\begin{aligned}
& \text { David A. Sbarra }{ }^{1} \text {, Julia L. Briskin }{ }^{2} \text {, \& Richard B. Slatcher }{ }^{2} \\
& 1 \text { = Department of Psychology, University of Arizona } \\
& 2 \text { = Department of Psychology, Wayne State University }
\end{aligned}
$$

In Press, Perspectives on Psychological Science. Accepted, 11.2.2018

This final accepted version may differ from published version as a function of changes that emerge during the copyediting process.

Word Count (total): 12,462

Tables: 1

Figures: 3

References: 147

Acknowledgements: Portions of this paper were delivered as talks by David Sbarra at the 2017 Mind \& Life Institute’s Summer Research Institute and by Richard Slatcher at the 2018 European Spring Conference on Social Psychology. The authors wish to thank Jeffry Simpson, 
Chris Segrin, and AJ Figueredo for helpful input on the ideas in this paper. Correspondence regarding this manuscript can be directed to either David Sbarra (sbarra@email.arizona.edu) or Richard Slatcher (rich.slatcher@gmail.com). 


\begin{abstract}
This paper introduces and outlines the case for an evolutionary mismatch between smartphones and the social behaviors that help form and maintain close social relationships. As psychological adaptations that enhance human survival and inclusive fitness, self-disclosure and responsiveness evolved in the context of small kin networks to facilitate social bonds, to promote trust, and to enhance cooperation. These adaptations are central to the development of attachment bonds, and attachment theory is middle-level evolutionary theory that provides a robust account of the ways human bonding provides for reproductive and inclusive fitness. Evolutionary mismatches operate when modern contexts cue ancestral adaptations in a manner that does not provide for their adaptive benefits. This paper argues that smartphones and their affordances, while highly beneficial in many circumstances, cue our evolved needs for self-disclosure and responsiveness across broad virtual networks and, in turn, have the potential to undermine immediate interpersonal interactions. We review emerging evidence on the topic of technoference, defined as the ways in which smartphone use may interfere with or intrude into everyday social interactions (either between couples or within families). The paper concludes with an empirical agenda for advancing the integrative study of smartphones, intimacy processes, and close relationships.
\end{abstract}

Keywords: technology, relationships, intimacy, smartphones, evolutionary mismatch, technoference 


\section{Smartphones and Close Relationships: The Case for an Evolutionary Mismatch}

Technology is a ubiquitous part of modern life. Worldwide, over two billion people own a smartphone (Pew Research Center, 2016), and 77\% of Americans go online on a daily basis, interacting on social networking sites (SNS) like Facebook, Twitter, Instagram, or Snapchat (Pew Research Center, 2018a). When we are not on our phones, we are on computers, sending emails or immersed in virtual worlds like Second Life, or completing other computer-mediated activities. When we're not on our computers, we are often watching TV or playing video games. More than a quarter of people in the United States report being online “almost constantly” (Pew Research Center, 2018a). In a recent survey, 46\% of adults reported that they "couldn't live" without their smartphones (Pew Research Center, 2015).

Understandably, the speed of movement toward humans' fully-networked existence has given rise to a body of journalistic, scholarly, and scientific research pursuits exploring the consequences of our ever-increasing reliance on and embeddedness in technology. An entire genre of popular books, for example, assesses the terrain of everyday technology use, including the way the internet is changing our brains (Carr, 2011), the ways in which our devices may create psychological distance in immediate social interactions (Turkle, 2011), whether our technology use can be considered behavioral addiction (Alter, 2018), and, perhaps of largest concern, whether generational differences in teenagers’ social behaviors are a causal consequence of the technological revolution (Twenge, 2017). The rapid speed of technological advances has created an urgency around questions of whether these developments are, prima fascie, good or bad. Of course, this is a false dichotomy; ultimately, the scientific evidence will likely conclude that there are many ways in which technology is (or, at least, can be) both good and bad. At this point, though, one observation is clear: We are living in a time of critical 
self-examination about the ways in which technology is dramatically reshaping the landscape of social behaviors and perhaps even the nature of social interaction itself. In the next 25 years, computer-mediated, virtual social interactions are expected to have a likeness to in-person interactions that are uncanny (Bailenson, 2018). As we approach the precipice of these changes, a careful evaluation of the likely or anticipated effects-and how we can better understand what is happening and what is to come-is a timely and perhaps necessary task for psychological science (cf. Pew Research Center, 2018b).

The current paper is nested under this larger study of technology and well-being. We focus, in particular, on evaluating the evidence for an emerging evolutionary mismatch between the ways in which smartphones (and their affordances - access to social networks, texting, etc.) may activate or take advantage of the basic intimacy processes required for forming and maintaining high-quality close relationships. Evolutionary mismatches are defined as situations in which human adaptations that emerged to foster reproductive and inclusive fitness in ancestral environments become maladaptive in novel contexts that may differentially cue the same adaptations, or evolved psychological mechanisms (Brenner et al., 2015; Li, van Vugt, \& Colarelli, 2017; Maner \& Kenrick, 2010). Within this framework, the modern environment cues ancestral adaptations that essentially "misfire” and do not provide for the same type of adaptive benefits. A classic and oft-cited example of the so-called mismatch is human's desire for sweettasting food, an adaptation that signaled nutritional value in ancestral environments. The contemporary food environment of most industrialized societies is replete with sugar-enhanced foods that contribute directly the global obesity pandemic (Brenner et al., 2015). In this case, the mismatch is quite obvious: Although adaptive in an ancestral context and vital for humans’ 
survival, sweet-tasting food no longer signals nutritional value, and the evolved preferences for sugar-enhanced food has become a health risk.

Recently, Li et al. (2017) proposed a framework in which the case for an evolutionary mismatch would be supported if (a) there is an identifiable and evolved mechanism with specific functions; (b) these functions are elicited by specific cues for the mechanism; (c) there is a discrepancy in the current and ancestral environment in the quantity, intensity, or constitution of input cues that elicit the mechanism; and, (d) the consequences of the mechanism's output reduce reproductive fitness. Further, in modern societies, mismatches occur most commonly when a new environment is imposed on an organism and/or when novel stimuli preferentially elicit the evolved mechanism (Li et al., 2017). Below, we argue that smartphones and their affordances, including easy access to SNS and near instantaneous two-way text-based communication, create a responsiveness draw that pulls people away from their immediate interpersonal interactions and into virtual interactions. These virtual interactions can provide innumerable benefits. However, a nascent literature suggests there is a potential downside as well, and that is a cost to our immediate, face-to-face relationships and our ongoing, real-time interactions.

The basic outline of our analysis is illustrated in Figure 1. The first section of the paper sets the stage for more detailed study by discussing general ways in which smartphones and their affordances are changing social interactions. The second section of the paper focuses on attachment theory as a middle-level evolutionary theory (Buss, 1995; Fletcher, Simpson, Campbell, \& Overall, 2015; Simpson \& Belsky, 2016) and the role of self-disclosure and responsiveness as evolutionary adaptations designed to solve the ancestral problem of cultivating cooperation and thus enhancing reproductive and inclusive fitness (cf. Lewis, Al-Shawaf, 
Conroy-Beam, Asao, \& Buss, 2017). We describe how and why self-disclosure and responsiveness are elicited in social contexts_-including those that are virtual and unfold online-and their critical roles as constituent behaviors in the development and maintenance of tight social bonds. We also identify the ways in which smartphones and their affordances exert a strong pull for self-disclosure and responsiveness. This section provides details for Panels A-C in

Figure 1. The third section reviews literature on potential consequences of the mismatch (Panels $\mathrm{D}$ and $\mathrm{E}$ in Figure 1). Here we focus narrowly on the topic of technoference, defined as the ways in which smartphone use may interfere with or intrude into everyday social interactions, either between couples or within families (McDaniel \& Coyne, 2016; McDaniel, Galovan, Cravens, \& Drouin, 2018; McDaniel \& Radesky, 2018). This section also includes coverage of the ways in which smartphone use may also disrupt basic cognitive processes needed to maintain intimacy. The closing section of the paper outlines an empirical agenda expanding research on technoference and the possible mismatch.

\section{INSERT FIGURE 1 ABOUT HERE}

From the outset, we acknowledge that the analysis presented here raises far more questions than it answers. We note, also, that this analysis is not the first to suggest that smartphones and social media cue ancestral adaptations. Writing from a social neuroscience perspective, for example, Tamir and Ward (Tamir \& Ward, 2015; Ward, 2013) discuss the ways in which contemporary technological advances activate basic reward systems and "hijack preexisting cognitive tendencies” (Ward, 2013; p. 341; also see: Tamir \& Ward, 2015, p. 442). The present contribution rests in extending these earlier ideas into a more complete mismatch 
framework with the ultimate goal of using this framework to derive empirically testable hypotheses as well as for developing a more complete and systematic understanding of how technology affects social relationships.

\section{Setting the Stage: Smartphones and Relationships}

Smartphones function as vastly instrumental tools for helping people meet their social, vocational, academic, health, and recreational goals (Bayer, Campbell, \& Ling, 2015). Smartphones allow people to strengthen important social ties in numerous ways (Campbell, 2015), often serving as a convenient tool for staying connected with friends, coordinating plans, and sharing jokes, thereby making communication "more personalized, direct, and timely" than ever before (Ling, 2012, p. 99). Lane and colleagues (2010) have argued that implementation of smartphone technology (specifically due to the phenomenon of “mobile sensing”) can potentially benefit people across many different domains, including health (Consolvo et al., 2008; Luxton, McCann, Bush, Mishkind, \& Reger, 2011), social networks (Miluzzo et al., 2008), and transportation (Thiagarajan et al., 2009), all in service of improving human potential and wellbeing. Indeed, there are thousands of smartphone applications to help track health, fitness, sleep, exercise habits, doctor visits, general activity, diet, mood, modes of transportation, and academic progress, and smartphones provide a variety of social platforms from which people can communicate with thousands of others, if desired.

Smartphones in relationships. With the arrival of smartphones in daily life-and the concomitant rise of social network sites (SNS) like Facebook, Instagram, Snapchat, and Twitter-technology use has also emerged as an area of frequent conflict among couples and families. A Pew Research Center study (Pew Research Center, 2014) of over 2,000 adults aged 18 and older found that $25 \%$ of couples in serious relationships reported that their partners had 
been distracted on a mobile phone while spending time together, and this number rises to $42 \%$ among couples 18-29 years old. A more recent and detailed sample of 143 married/cohabiting women reported that cell phones/smartphones interfere "sometimes, often, very often, or all of the time” in 70\% of the sample (McDaniel \& Coyne, 2016). As we describe below, it is not a coincidence that smartphones exert a large pull for our attention. To the extent that our desires to self-disclose and be responsive to others (a) draws us away from our immediate (face-to-face) interactions with close others and toward our devices, and (b) is perceived by a partner or close other as a loss of responsiveness, we expect that relationship conflict and negative personal consequences (e.g., lower well-being, greater loneliness) will follow.

Of course, conflict over divided attention is nothing new. It is not hard to imagine one person becoming upset with his spouse's incessant reading of the newspaper (or vice versa) while he is trying explain the frustrations of his workday. In many ways, smartphones and their affordances only up the ante on this dynamic. Recast, this process can be understood as the foundation for a relatively classic mismatch in which new input cues_-virtual and online social contexts that pull for self-disclosures and responsiveness in our social networks—are increasing in intensity and quantity ( $\mathrm{Li}$ et al., 2017). For example, scholarship in a range of diverse fields also suggest that smartphones are giving rise to altered patterns of social interactions, many of which require a new lexicon to describe. We now have phrases to describe behaviors that did not exist just two decades ago, including not only technoference, but phubbing and Pphubbing (described, respectively, as the ways in which people can snub each other with their phones, and the ways in which romantic partners may snub each other with their phones; Roberts \& David, 2016); the problems of absent-presence and being alone together, and micro-social fragmentation (wherein people occupy the same physical space but have their attention diverted into their 
devices and away from real-time interpersonal exchanges; Gergen, 2002; Turkle, 2011); the horizontalization of relationships (in which networks move from being distributed vertically as smaller and interpersonally deeper to horizontally as broader but more shallow; Gergen, 2002) and FOMO (anxiety around the "fear of missing out" on social exchanges; Przybylski, Murayama, DeHaan, \& Gladwell, 2013), which may give rise to nomophobia (the fear of being without one’s mobile device; King et al., 2013).

In her seminal exploration of the ways in which technology is reshaping modern life, Turkle (2011) is clear in illustrating the double-edged sword of what she calls the tethered existence. Although the affordances of mobile devices and SNS are immediately apparent, some of the consequences, especially to our relationships, are not. Turkle (2011) writes:

“And yet, in the half-light of virtual community, we may feel utterly alone. As we distribute ourselves, we may abandon ourselves. Sometimes people experience no sense of having communicated after hours of connection. And they report feelings of closeness when they are paying little attention. In all of this, there is a nagging question: Does virtual intimacy degrade our experience of the other kind, and, indeed, of all encounters of any kind?” (p. 12).

\section{The Evolution of Social Bonding and Human Attachment}

Developing ideas around a potential evolutionary mismatch between ancestral social relationships and the pull of modern technology first requires the identification of an evolutionary adaptation that promoted human survival (Li et al., 2017); this first step necessitates a focus on the environment of evolutionary adaptiveness (EEA) and the problems ancestral humans faced that impacted their survival and reproduction (Lewis et al., 2017). We open this section with a focus on Panels A and B in Figure 1. Humans have a fundamental need to form 
close attachments with others (Baumeister \& Leary, 1995), and this need has its evolutionary roots in our earliest mammalian ancestors more than 250 million years ago. Indeed, attachment theory (Bowlby, 1969/1982) is a middle-level evolutionary theory that provides a robust account of the ways in which close relationships and social bonds provide for reproductive and inclusive fitness (Simpson \& Belsky, 2016) ${ }^{1}$.

The EEA and emergence of affiliative behaviors. Evolutionary accounts of social bonding suggest the attachment system emerged to solve specific problems in the EEA, including providing safety for immature infants in physically harsh conditions, as well as safety for adults living in groups (Kaplan, Hill, Lancaster, \& Hurtado, 2000). According to Lewis et al. (2017), evolutionary problems that were "high frequency, high impact"-that is, adaptive problems that were both frequently encountered and highly impactful for survival—exerted especially strong selection pressures and gave rise to important psychological adaptations to address them. It is very likely that dangerous living conditions in ancestral environments (e.g., contact with wild animals, experiencing harsh weather, and competing for scarce resources with rival group members) were experienced frequently and were often life-threatening. In this context, affiliative behaviors promoting trust, cooperation, and the formation of strong social (attachment) bonds were imperative to humans’ survival and their reproductive fitness. Indeed, some authors argue that attachment is not just vital for human infants’ survival but that a system designed to keep people socially connected was the central problem of mammalian evolution (Lieberman, 2013). Simpson and Belsky (2016) note that in the EEA, "Participation in the daily

\footnotetext{
${ }^{1}$ Middle-level evolutionary theories are propositions about domains of functioning and give rise to specific hypotheses about evolved behavioral adaptations in those domains (see Buss, 1995). Bowlby's (1969/1980) attachment theory is also a middle-level theory because it outlines a universal suite of cognitive and affective behaviors that bind humans together in service of reproductive and inclusive fitness (Simpson \& Belsky, 2016).
} 
functioning of small, cooperative groups may in fact have been the predominant survival strategy of early humans (Brewer \& Caporael, 2006)” (p. 96). This perspective is consistent with broader anthropological accounts of humans' sociality. The anthropologist Robin Dunbar, for example, argues that it is because of the increasing complexity of our social relationships-driven by the increasing size of our non-kin social groups_-that humans developed such large brains relative to the size of our bodies (Hill \& Dunbar, 2003). From this perspective, often referred to as the social brain hypothesis (Dunbar, 2003), the primary reason our neocortext grew so large is so humans could live in increasingly larger social groups and be more highly social. Humans’ sociability and the social emotions needed to navigate close relationships-including tenderness, guilt, remorse, jealousy and love itself-emerged in the context of the EEA to promote cooperation, trust, and, in select relationships, an attachment bond. We argue below that cooperation, trust, and attachment hinge on interpersonal intimacy. Viewed from this perspective, self-disclosure and responsiveness, the social behaviors contributing to intimacy, are among interpersonal building blocks of attachment relationships, and these behaviors help solidify the bonds that promote humans’ survival.

A hallmark of being human is that we form intimate relationships with both kin and nonkin. Intimate relationships are characterized by a deep sense of emotional closeness toward another person (Aron, Aron, \& Smollan, 1992) and usually are characterized by frequent, strong and diverse contact (Kelley et al., 1983). On average, people have between 3 and 7 people with whom they interact at high levels of intimacy, about half of whom are usually non-kin (Milardo, 1992). In ancestral times, a person’s intimate network functioned, above all, as a security network that provided the individual with unspoken and unquestioning support, to help combat the adaptive problem of harsh and dangerous living conditions. These relationships depended on 
face-to-face contact and frequent reaffirmation, and it is from their intensity that individuals derived security—-security that one could trust that those in their intimate network would be there in times of trouble and that they would not be excluded from the group. Shared risk taking in hunting and protecting young shows that early humans not only took risks on behalf of the group (demonstrating the importance of cooperative bonds to enhance the odds of survival), but were able to trust those in their intimate networks to do so equally, thereby ensuring that cooperative relationships were mutually beneficial (Plummer, 2004). A primary constraint of intimate relationship networks was their size. The number of people with whom one could interact at such an intensity_at least in ancestral times_-was relatively limited. Beyond intimate networks were so-called effective networks of friends and relatives (around 20 people), and extended networks (around 100-400 people) that included acquaintances and friends of friends (Gamble, 1998). Effective network members are often those who provide emotional and material assistance in daily life—not as emotionally deep as intimate network members, but still people with whom one would spend substantial face-to-face time on a regular basis.

A good example of an effective network was described in Thrasher's (1927) classic study of Chicago neighborhood adolescent male gangs. In a sample of 895 gangs, 90\% had fewer than 50 members while $60 \%$ ranged in size from six to twenty members. Thrasher explained the typical gang size, or clique, by the necessities of maintaining face-to-face relationships. Extended networks, in contrast, are much larger, require little face-to-face contact, and vary in whether they are active or passive. In earlier times, the extended network would have included entire tribes of people, including those one barely knew and distant kin (Gamble, 1998). Probably not coincidently, the size of extended networks in ancestral times is mirrored today in the typical size of one’s online social network (Dunbar et al., 2015). 
In summary, what is clear from archaeological records and cross-species comparison is that human brains not only evolved to deal with the immense complexities of social relationships, but that they were especially well designed for navigating close and intimate relationships with non-kin, including potential romantic partners. Furthermore, the adaptive psychological mechanism of creating attachment bonds and cooperating with others was particularly important to increase the chance of surviving and reproducing when facing the "high frequency, high-impact” problems in the EEA (Lewis et al., 2017). Indeed, romantic love is believed to be an evolved and universal “commitment device” designed to facilitate pair-bonding and the persistence of the bond in time (Fletcher et al., 2015). Central to our mismatch hypothesis is the observation that core intimacy processes - that is, self-disclosure and responsiveness, which play a critical role in both human cooperation and human bonding (Reis, Clark, \& Holmes, 2004)—are evolved behavioral adaptations.

Core intimacy processes: Self-disclosure and responsiveness. Although most of what we know about ancestral social relationships relies on archaeological data, what we know about the nature of intimacy is based on voluminous research with modern-day humans. A core building block of intimacy is self-disclosure. Roughly 30-40\% of everyday speech is used to convey information to others about one’s private experiences or personal relationships (Dunbar, Marriott, \& Duncan, 1997; Emler, 1990, 1994; Landis \& Burtt, 1924). Evolutionary theorists argue that such high rates of self-disclosure reflect an adaptive motivation to share our beliefs and knowledge about the world with others (Csibra \& Gergely, 2011; Tomasello, 1999). Opportunities to self-disclose are experienced as a powerful form of subjective reward, in the same way as with primary rewards such as food and sex. As evidence, Tamir and Mitchell (2012) showed that self-disclosure was strongly associated with increased activation in brain 
regions that form the mesolimbic dopamine system, including the nucleus accumbens and ventral tegmental area. Moreover, they showed that people are willing to forgo even money to disclose about the self.

Disclosure of one’s inner thoughts and feelings to another person leads to liking and caring, ultimately fostering the deepening of a relationship (Altman \& Taylor, 1973; Chelune, Robison, \& Kommor, 1984; Collins \& Miller, 1994; Jourard, 1971). Importantly, self-disclosure is a key signal of trust in social relationships (MacDonald, Kessel, \& Fuller, 1972) and the association between self-disclosure and trust becomes stronger as relationships become deeper (Larzelere, \& Huston, 1980). In the EEA, self-disclosure would have conferred adaptive benefits through several routes: facilitating social bonds and alliances within one's group (Collins \& Miller, 1994; Dunbar, 2003; Greene, Derlega, \& Mathews, 2006), improving outcomes in decision making (i.e., "two heads are better than one”; Bahrami et al., 2010), and by getting feedback from others to gain knowledge about the self (Derlega, Metts, Petronio, \& Margulis, 1993).

Getting feedback from others is especially critical in the development of intimacy. Although self-disclosure is a key ingredient of intimacy, it is an insufficient one. Theorists argue that in order for self-disclosure to lead to close social bonds, it must be followed by responsive behaviors by the listener that convey understanding, validation and warmth to the speaker (Reis \& Shaver, 1988). When the speaker in turn perceives the listener to be responsive-termed perceived partner responsiveness—-feelings of closeness develop. A large literature provides evidence for this interpersonal process model of intimacy, showing that self-disclosure is associated with intimacy via responsiveness (for a review, see Reis, Clark, \& Holmes, 2004). Maternal responsiveness directly fosters feelings of security in infants (Ainsworth, Blehar, 
Waters, \& Wall, 1978), a process later mirrored in adult romantic relationships (Hazan \& Shaver, 1987). Putting a point on this observation, Lieberman (2013) argues that "the price for our species’ success at connecting to a caregiver is a lifelong need to be liked and loved” (p. 48). A specific manifestation of this need is responsiveness. In adulthood, responsiveness is strongly associated with trust, commitment and feelings of closeness in dyadic relationships (Reis, Clark, \& Holmes, 2004) and with increased perception of cooperative intentions in small groups (Gefen and Ridings, 2002). From a normative, species-typical perspective, human attachments promote reproductive and inclusive fitness, and self-disclosure and responsiveness are among the key behaviors that shape these bonds. Said differently, we appear evolutionarily prepared to build closeness with others via the twin processes of self-disclosure and responsiveness, and we can trace this preparedness to the adaptive problems faced by early humans in the EEA.

Intimacy, health, and well-being. To substantiate our mismatch framework, we argued above that self-disclosure and responsiveness are behavioral adaptations that emerged in the EEA to promote social bonds and thus provide for inclusive and reproductive fitness. In this subsection, we review literature on the health benefits of social bonds and, especially, intimate relationships. Critically, this research, in-and-of itself, is not intended to support the case for the evolved importance of intimacy, although it does at least peripherally in the sense that a survival advantage is clearly relevant to reproductive and inclusive fitness (cf. Fletcher et al., 2015); rather, we review work on the importance of close relationships for health and well-being as relevant background for understanding what is at stake in cases of technoference. Said differently, we do not believe that technoference disrupts health in any real way, but we do believe that technoference can disrupt relationships in important ways. 
Relationship quality is associated with a range of important health outcomes. In adulthood, having strong and high-quality social ties is essential for happiness (Diener \& Seligman, 2002), and relationship quality is associated with a range of health outcomes, including risk for early mortality (Holt-Lunstad, Smith, Baker, Harris, \& Stephenson, 2015; Holt-Lunstad, Smith, \& Layton, 2010). The effects of social relationships on longevity are equal to or exceed those of other, hallowed healthy behaviors such as physical activity and good nutrition, and increasingly, improving social relationships is becoming a public health priority in the United States and around the world (Holt-Lunstad, Robles, \& Sbarra, 2017). Beyond the sheer presence or absence of social ties being associated with health, the quality of close relationships matters as well (Robles, Slatcher, Trombello, \& McGinn, 2014; Slatcher \& Selcuk, 2017). Researchers are now beginning to identify the key aspects of high-quality relationships associated with health and well-being that might be modifiable targets for intervention. The core intimacy processes of self-disclosure and responsiveness are promising targets.

A large body of experimental evidence has shown that disclosing one's thoughts and feelings through expressive writing results in improvements in physical health (Frattaroli, 2006) and improved functioning of the hypothalamic-pituitary-adrenal (HPA) axis (Smyth, Hockemeyer, \& Tulloch, 2008; van Middendorp, Geenen, Sorbi, van Doornen, \& Bijlsma, 2009), which produces the stress hormone cortisol. Recent evidence indicates that disclosures in everyday life in the context of close relationships are beneficial for health-related processes as well. For example, self-disclosure between spouses is associated with a buffering of the physiological effects of work stress on daily cortisol production (Slatcher, Robles, Repetti, \& Fellows, 2010) as well as improved sleep quality (Kane, Slatcher, Reynolds, Repetti, \& Robles, 2014). Increasingly, researchers are homing in on partner responsiveness as a key social driver of 
health and well-being. Responsive interactions foster intimacy in couples (Debrot, Cook, Perrez, \& Horn, 2012) as well as improved interactions between leaders and subordinates (Kluger \& Zaidel, 2013) and between physicians and patients (Reis et al., 2008). Responsiveness is also linked to greater personal well-being, including greater emotional well-being among cancer patients (Otto, Laurenceau, Siegel, \& Belcher, 2015), improved ability to integrate negative life experiences into the self-concept (Weeks \& Pasupathi, 2011), and greater hedonic and eudaimonic well-being in the U.S. and Japan, but especially in the U.S. (Tasfiliz et al., in press). Because responsiveness shares common elements with a number of important relationship constructs — facilitating core validation of the self, and fostering feelings of warmth, acceptance, belonging, and trust-it has been deemed an organizing principle in the study of relationships (Reis, 2012), including in the study of relationships and health (Slatcher \& Schoebi, 2017).

In infancy, responsiveness from attachment figures facilitates 'tuning and pruning' of stress biology systems, and, in turn, long-term health benefits via improved stress regulation (Meaney, 2010). Studies of parenting support this idea, with greater maternal responsiveness associated with better functioning of the HPA axis (Gunnar \& Quevedo, 2007) and lower levels of inflammation (Tobin et al., 2015). A recent investigation tested whether fine-tuning of the HPA axis by responsive close others might extend into adulthood. In a large sample of married and cohabitating adults, greater perceived partner responsiveness predicted steeper ('healthier') diurnal cortisol slopes 10 years later (Slatcher, Selcuk, \& Ong, 2015), and was associated with better sleep (Selcuk, Stanton, Slatcher, \& Ong, 2017), even after controlling for relevant demographics, personality traits, and other important relationship factors.

Partner responsiveness is also linked to improved regulation of physical pain. For example, responsive interactions with partners are associated with increased release of 
endogenous opioids, which lessen the experience of pain and also promote felt security and commitment (Machin \& Dunbar, 2011). Indeed, holding hands with a romantic partner makes physical pain more bearable (Eisenberger et al., 2011) and fosters recovery from recalling emotionally painful experiences (Selcuk, Zayas, Günaydin, Hazan, \& Kross, 2012). Responsive relationships may also help relieve chronic physical pain, a hypothesis supported by the finding that greater partner responsiveness predicts reduced pain three months after knee replacement surgery (Khan et al., 2009).

In summary, a large body of evidence indicates that the intimacy processes of selfdisclosure and responsiveness foster close social relationships, and ultimately, better health and well-being. Below, we review findings suggesting that today’s technology-especially smartphones_-capitalizes on this evolved brain architecture, drawing in its users through its ample opportunities for self-disclosure and cues to responsiveness.

Intimacy processes in the modern world. Thus far, we have argued that in the EEA, humans faced numerous adaptive problems that necessitated strong affiliative bonds and cooperation to increase the odds of survival. Social behaviors that enhanced the potential for cooperation and provided for security (i.e., trust) within these relationships improved reproductive and inclusive fitness. Under these conditions, interpersonal intimacy—shaped through self-disclosure and responsiveness_-provided adaptive value in building and maintaining close social bonds. Of course, the modern environment in which humans live today has changed dramatically from the EEA, and in this section of our mismatch analysis (corresponding to Panel C in Figure 1), we discuss the ways in which smartphones and their affordances create a unique and entirely unprecedented pull for disclosure and responsiveness. The case for an evolutionary mismatch requires evidence not just that modern society is different 
from ancestral environments, but, more precisely, that modern society cues psychological mechanisms in excess, or in ways that preferentially elicit the mechanism toward maladaptive consequences. Li et al. (2017) refers to these mismatches as those that are "forced" or “hijacked,” respectively (also see Tamir \& Ward, 2015).

As we noted early on in this article, it is hard to overestimate the fundamental shift in how people communicate with one another in the last 10+ years, since the release of the first iPhone in 2007. As of late 2016, over 77\% of all Americans owned a smartphone, including 92\% of those aged 18-29 (Pew Research Center, 2017). Not only do most Americans now own smartphones, but they use them a lot —on average for 5 hours a day. Much of that time is spent on social media, such as Facebook, Twitter, Snapchat, and Instagram. Worldwide, people spent an average of 135 minutes per day on social media in 2017, up from 126 minutes in 2016 (Statista, 2018a). In the U.S., 60\% of social media time is spent via smartphone applications (Statista, 2018b). Thus, more and more, people are turning to social media to "talk" to friends and acquaintances, often via their smartphones. Further, online social communication may be serving as a substitute for face-to-face interactions. Online time is negatively correlated with time spent going to parties, attending cultural events, and socializing with people in a variety of offline contexts (Wallsten, 2013). As Tamir and Ward (2015) put it, “As social animals in a digital world, we seem to obsessively log on, tune in, and exchange face-to-face interaction for social content delivered through a screen” (p. 432).

Social network activities are built on self-disclosure and responsiveness. One purpose of social media is to share facts and one's thoughts and feelings (or photos or links to articles) to a large number of people and, in turn, for those in one's online social network to respond. In other words, the success of social media is built on the processes of self-disclosure and 
responsiveness. Some authors have gone as far as suggesting that SNS have "hijacked" the human need to self-disclose (Tamir \& Ward, 2015, p. 442). Whereas in-person social interactions are usually limited in the size of their audience for sharing things about the self, online sharing can happen with an audience that is limitless in size. Throughout evolutionary history, the process of self-disclosure unfolded between two or at most a few people, but we can now tell hundreds, thousands, and even millions of people about our experiences at the click of a button. And this is what most of us are doing online-over $80 \%$ of social media activity involves simply announcing or broadcasting one’s immediate experiences (Naaman, Boase, \& Lai, 2010). If ample opportunities to self-disclose provided the spark for people’s interest in social media, responsiveness provided the fuel. On February 9, 2009, Facebook introduced the "like” button (Morgans, 2018). This rendered the need for Facebook users to comment on status updates, photo uploads or other posts obsolete; instead, users can simply "like” it with the click of a button that signaled a thumbs-up. Since then, other social media platforms (Instagram, Twitter and YouTube) have followed suit with their own versions of the like button (in the case of Instagram and Twitter, a tiny heart) to let users respond positively to people's posts. Thus, not only can one socially share with an infinite number of people, but one can also be responded to (or ignored) by an infinite number.

By having the ability to share and be responded to by so many people at once on social media, are people achieving deep social connections with others, or are such social connections partly illusory? That question has not yet been fully answered, but data from several studies have suggested that SNS activity may, under certain circumstances, increase the risk of mental health problems (Guernsey, 2014; Morrison \& Gore, 2010; Selfhout, Branje, Delsing, ter Bogt, \& Meeus, 2009), detract from face-to-face relationships (Leung \& Lee, 2005), reduce investment in 
meaningful activities (Leung \& Lee, 2005), and negatively impact well-being generally (Kross et al., 2013; Neira, Corey, \& Barber, 2014; Sagioglou \& Greitemeyer, 2014; Selfhout, et al., 2009; Van den Eijnden, Meerkerk, Vermulst, Spijkerman, \& Engels, 2008). Only a handful of studies have suggested that social media has an overall positive impact on social connectedness and well-being (Kim \& Lee, 2011; Nabi, Prestin, \& So, 2013; Valenzuela, Park, \& Kee, 2009). Almost all of the research in this area has been cross-sectional, but a recent study of 5,208 Americans across three waves of data (2013, 2014, and 2015) from the nationally representative Gallup Panel Social Network Study examined how online (on Facebook) and offline (i.e., in person) social interactions were independently associated with several subjective measures of well-being. A recent analysis of data from this study found that the use of Facebook (the most widely used and studied social network site) was negatively associated with well-being, both cross-sectionally and longitudinally (Shakya \& Christakis, 2017). In a prospective analysis, Shakya and Christakis (2017) found that greater Facebook use at Time $t$ (e.g., more "likes clicked” on articles, friends’ Facebook pages, and status updates) was associated with decreases in self-reported mental health and well-being at Time $t+1$, controlling for self-reported mental health at time $t$. Further, the negative associations of Facebook use were comparable to or greater in effect size than the positive impact of offline interactions in the same sample of Gallup participants.

Although it is beyond the scope of this paper to fully examine whether SNS activity reliably or definitely decreases psychological well-being in its many forms, the nascent evidence base suggests that, at least under certain conditions, it can do so, and the central question becomes understanding why and when this is the case. Recently, Nowland, Necka, and Cacioppo (2017) advanced the argument that social technologies increase loneliness when they are used to 
withdraw or escape from the "social pain” of in-person social interactions. We agree with this analysis, and suggest that it can be extended: Missing out on social opportunities is not the same as being drawn away from in-person interactions and into the virtual world. Smartphones and their affordances pull for both self-disclosure and responsiveness, and the sheer ubiquity and ease of access associated with the devices allows us to connect to the entirety of our social network at any given moment; the devices also allow our network to be in touch with us and pull for our responding at any given moment as well.

From this perspective, it is reasonable to argue that in close relationships, an evolutionary mismatch occurs when smartphones and their affordances permit the outer layers of our extended social network (Gamble, 1998) to activate basic intimacy processes. For example, consider a family of two parents and two kids having dinner together. An aunt from a distant state starts posting pictures on Facebook of a summer trip with all the cousins. In the middle of a conversation about the school day, the family pauses to begin responding to the aunt via their smartphones. On one hand, this might be quite positive for the family, with the opportunity to see their cousins and appreciate the fun trip of relatives. On the other hand, the draw to respond in near real-time diverts attention from and potentially fragments a conversation about the school day or the slings and arrows of parents' work (see Gergen, 2002). This attention-grabbing dynamic unfolds many times a day across many social contexts, where the twin desires to disclose information about the self and to be responsive to others draw us out of or away from our immediate interactions and into the virtual world of our smartphones.

The mismatch framework allows us to view potential concerns about smartphones and their affordances on at least two levels. First, we can speculate, as many others have as well (see Rowland et al., 2017), that networked interactions provide only a verisimilitude to in-person 
social exchanges. Social media systems by design (with the exception of dyadic private messaging and small group features that are occasionally used on these systems) are geared toward fostering very public and often superficial disclosures that are simply not the sort of disclosures that foster feelings of closeness with others. It is only through deep self-disclosure, and perceived responsiveness to these disclosures, that feelings of intimacy and closeness form (Aron, Melinat, Aron, Vallone, \& Bator, 1997; Reis \& Shaver, 1988). Although high amounts of disclosure can happen online (e.g., through email, text, direct message, or other dyadic routes), most online interaction is not of that nature but in more public forums where true intimacy is difficult if not impossible. We theorize that social media specifically_and time spent online more generally —is not "bad” per se for forming social connections, but simply not well-suited for forming deep and meaningful connections. When shallow self-disclosure and responsiveness online—what might be termed “social snacking” (Gardner, Pickett, \& Knowles, 2005)—replaces (rather than supplements) in-person self-disclosure and responsiveness, we predict declines in feelings of social connection, and, in turn, declines in health and well-being (also see Nowland, et al., 2017).

Second, and perhaps at a deeper level, the adaptive value of humans’ proclivities toward self-disclosure and responsiveness is at odds with the affordances of smartphones. In this case, because SNS and real-time text messaging exchanges pull for disclosure and responsiveness (Panel C in Figure 1), broad social networks regularly activate adaptations that are critical for forming and maintaining close social ties. At any given moment, the phone compels people to engage intimacy processes with the farthest reaches of their social networks. Arguably, an important potential consequence of this shift in resources is that the ability to be present, attentive, and responsive to a partner or family member in the moment is diminished or, 
minimally, taxed on a regular basis; the same adaptations for building close social bonds in intimate networks are engaged in a manner that draws us away from real-time social interactions and into the virtual world. Viewed from this perspective, an obvious question emerges: Is there an existing or even emerging evidence base to suggest that smartphone use has the potential to undermine relationship quality?

\section{The Social and Cognitive Effects of Technology Use: A Review of the Current Findings}

We have argued that smartphones and SNS create a responsiveness draw that directly competes for humans' evolved desires to be responsive to social bids and to perceive others as responsive to our bids as well. This competition operates when smartphones usurp attentional resources that are typically allocated to in-person social interactions, undermining one's ability to both perceive responsiveness and to be responsive in the moment. In this section, which corresponds to the Panel D in Figure 1, we systematically review the empirical evidence on technoference and work suggesting that smartphones and their affordances can disrupt the basic social-cognitive processes required for perceived partner responsiveness. Specifically, we propose that smartphones and SNS disrupt attentional resources and undermine basic cognitive processes, which in turn disrupt relationship processes, and may ultimately lead to decreases in health and well-being. Below, Figure 2 “zooms in” on Panel D from Figure 1, illustrating the process by which smartphones and SNS disrupt cognitive, and in turn, relationship processes. In the sections below, we review literature that supports each numbered link displayed in Figure 2, with key findings summarized in Table 1.

INSERT FIGURE 2 ABOUT HERE 
Although the focus of this section is on the ways in which smartphones can yield negative consequences for relationships, we recognize that evidence for technoference must be viewed in light of the many positive features of smartphones and ways they can enhance relationship connection and quality. We emphasize that smartphones themselves are not "good" or "bad," but how they are used and when they are used can make smartphones instruments for success or agents of failure. In this next section, we focus on the empirical evidence to support paths 1, 2, and 3 in Figure 2.

\section{Technology Use and Cognition}

When attention is split, people are less able to perceive unusual things in their environment (Hyman et al., 2009), and it stands to reason that people are similarly less able to perceive subtleties in their environment. For example, it may be more difficult to pick up social cues when one's attention is split between one's phone and one's partner-when a person is looking at the phone instead of his/her partner, the partner's nonverbal cues are likely to be missed (represented by Paths 1 and 2 in Figure 2). Evidence from the communications literature suggests that people who are using their phones during in-person interactions are less able to pick up on cues of dissatisfaction with the conversation, are less able to understand their partners, and are perceived as being uninterested in the in-person interaction. For example, one small but qualitatively rich study of 25 college students (Aagaard, 2016), suggested that engagement with phones during face to face interactions resulted in perceived delays of responses, mechanical verbal communication, and a lack of appropriate expressiveness (i.e., reduced eye contact, lack of facial expression, head nodding, etc.), which contributed to 
perceptions of interaction partners as uninterested and lacking empathy. Additionally, participants reported that when they use their own smartphones during in-person interactions, they are less able to hear and focus on what their interaction partner says (Aagaard, 2016), demonstrating the smartphone’s capacity to usurp attentional resources (supporting paths 1, 2, and 3 in Figure 2; See Table 1). Although it is important to understand the associations between smartphone use and relationship processes, it is also important to consider why these associations exist, and this question points to the study of basic social-cognitive processes that can be disrupted by smartphones (i.e., perception and attention). We argue that disruptions in these processes can translate into disruptions in social interactions.

Smartphones and cognition. There is considerable evidence suggesting that technology use disrupts basic cognitive processes, including those that are critical to the creation and maintenance of interpersonal intimacy. Just as the mere presence of smartphones can disrupt interpersonal interactions (Przybylski \& Weinstein, 2013; Misra et al., 2016; Sprecher et al., 2016), the mere presence of smartphones can disrupt basic cognitive processes (represented by path 1 in Figure 2). For example, Thornton, Faires, Robbins, and Rollins (2014) showed that people performed worse on the difficult part of a Trail Making Task (TMT) in the presence of a phone (versus presence of a notebook), and they further showed that it was the quality of the TMT performance that suffered (indexed by the number of correct lines drawn in the TMT), rather than the quantity of lines drawn in the TMT (which was approximately equivalent between the smartphone and notebook conditions).

The mere presence of smartphones can also reduce working memory capacity; in an experimental study, Ward, Duke, Gneezy, and Bos (2017) showed that performance on the Ospan task suffered in the presence (versus absence) of the participants' smartphones. Other work 
shows that receiving even a single smartphone notification (Stothart, Mitchum, \& Yehnert, 2015) can be disruptive to one's attentional resources, and in turn, cognitive performance, particularly for highly demanding tasks. Stothart and colleagues (2015) showed that performance on the Sustained Attention to Response Task (SART) suffered when participants received a notification on their phone during the task (prompting “task irrelevant thoughts”), compared to when they performed the task without being interrupted by a phone notification (supporting path 1 from Figure 2; see Table 1). This effect emerged despite participants’ inability to engage with their phone in either instance (Stothart et al., 2015).

In their review of technology habits and cognitive functioning, Wilmer and colleagues (2017) argue that smartphones disrupt cognition in two primary ways: endogenous, or unsolicited disruption (when thoughts naturally "drift” to the smartphone due to boredom with the environment, or dissatisfaction with a primary task), and exogenous disruption (when one is on the phone for one disruptive task, but the disruption continues when additional, unrelated apps prompt further smartphone engagement), suggesting that smartphones may uniquely undermine cognitive function due to their “double pronged” disruptive nature. In line with this idea, one experimental study (Levy, Rafaeli, \& Ariel, 2016) found that when participants were interrupted by a multimedia text message (a text message that displayed graphics as well as text) while playing a competitive online game (the primary task), they performed worse than participants who were interrupted by a multimedia message via the computer; unsurprisingly, uninterrupted participants performed the online game best. This suggests that although media message interruptions are generally detrimental to cognitive performance, media messages that are received via one’s smartphone are especially disruptive (Levy et al., 2016), presumably because of the potential for other apps on the smartphone to prolong the disruption. 
The current section detailed how technology use can disrupt cognitive processes, focusing on the first path proposed in Figure 2. Although there is little empirical evidence for the second path proposed in Figure 2, we argue that to the extent that attention is necessary for relationship processes to unfold (e.g., self-disclosure, responsiveness), the studies illustrating impaired cognitive functioning support this second theoretical link. In the next section, we turn our attention to how technology use affects relationships directly (path 3 in Figure 2), how technology use can affect one’s well-being (path 4 in Figure 2), and finally, how the link between technology use and well-being may be at least partially explained by disruptions in close relationships processes (path 5 in Figure 2).

\section{Technology and Social Relationships}

In the past five years, research on technology and interpersonal relationships has steadily increased, and much of this work focuses on the potential negative influences that smartphones and technology can exert on interpersonal relationships (McDaniel \& Coyne, 2016; Przybylski \& Weinstein, 2013; Roberts \& David, 2016; Vanden Abeele, Antheunis, \& Schouten; 2016). Research in this area can be divided into three broad categories: (1) Mere presence studies (focusing on the effect of the mere presence of smartphones or similar mobile technologies on cognition and relationship functioning; Paths 1, 2, and 3 from Figure 2), (2) Technoference studies (focusing on how partner phone snubbing and engagement with mobile technology while in the presence of partners can undermine relationship functioning; Paths 3 and 5 from Figure 2), and (3) Social networking studies (focusing on both the positive and negative aspects of using social networking sites for relationship functioning and well-being; Paths 4 and 5 from Figure 2). The mere presence studies, technoference studies, and social networking studies collectively 
provide support for the numbered paths presented in Figure 2, and the specific studies that support these linkages are highlighted in the review below, and summarized in Table 1.

Mere presence studies. The responsiveness draw of smartphones and mobile technology is so profound that their mere presence has been shown to disrupt relationship processes. For example, an experimental study by Przybylski and Weinstein (2013) showed that the presence (versus absence) of a smartphone led to reductions in relationship satisfaction for people who were interacting for the first time, especially when they were speaking about a topic of importance. Specifically, participants who were instructed to discuss the most important events that occurred in the last year (i.e., the condition that called for a great deal of self-disclosure) reported significantly reduced relationship quality, trust, and perceived empathy in the mere presence (versus absence) of a partner's smartphone, compared to participants who were instructed to casually discuss plastic holiday trees (supporting Path 3 from Figure 2; see Table 1). This suggests that there is something aversive about simply having a mobile device present, and its potential to disrupt an in-person interaction is sufficient to negatively affect one's interaction experience, particularly when the phone represents a threat to an important topic of conversation. Furthermore, these findings suggest that one's availability to others (via the smartphone) represents a competition for the attentional resources of an interaction partner (supporting Paths 1, 2, and 3 in Figure 2; See Table 1), which is especially detrimental to relationship processes when one is self-disclosing meaningful information (e.g., the most meaningful events in the past year). Misra, Cheng, Genevie, and Yuan (2016) conducted a conceptual replication of Przybylski and Weinstein’s (2013) Study 2 in a naturalistic setting with dyads in coffee shops; dyads were observed unobtrusively while discussing either (1) holiday trees (control condition) or (2) the most meaningful events that occurred during the past year (meaningful topic condition). Misra 
and colleagues (2016) replicated the work of Przybylski and Weinstein (2013), showing that the absence (versus presence) of mobile phones significantly positively predicted reports of connectedness after the dyads’ ten-minute conversation (however, unlike Przybylski and Weinstein’s 2013 results, they did not find that conversation topic moderated feelings of connectedness).

More recently, Sprecher, Hampton, Heinzel, and Felmlee (2016) found that unacquainted dyads interacting via Skype did not differ in their ratings of affect or conversation quality when one interaction partner unobtrusively used a smartphone (out of view of the interaction partner) versus when neither interaction partner used a smartphone. Interestingly, they found that those who unobtrusively used a smartphone during the Skype interaction were significantly less engaged in the interaction, yet this decreased engagement was not detrimental to self-reported conversation quality by the actor or the partner, suggesting perhaps that the presence of the smartphone must be perceived by an interaction partner before it exerts any negative effect on inperson interactions. These findings also suggest that participants may not have perceived any competition for an interaction partner's attentional resources (or, perhaps, that competition for attentional resources is more normative in the context of an online interaction). It should be noted that participants may have attributed seemingly occasional lapses of attention to the slight delays that can occur when using Skype as an interaction medium, thus the expectation of slight communication difficulties via Skype may have contributed to interaction partners being more “forgiving” of occasional conversation disengagement. Two of the “mere presence” studies were conducted with unacquainted individuals, and there is reason to believe that smartphones may be particularly detrimental to relationships that have already been formed (e.g., romantic couples). 
“Technoference” studies: Phubbing, conflict, and satisfaction. Other studies have extended the mere presence work by examining explicit use of technology and smartphones in the presence of partners. For instance, in a longitudinal online study with committed romantic couples, Halpern and Katz (2017) showed that greater self-reported frequency of texting was associated with a reduction in relationship quality one year later; furthermore, relationship satisfaction at Time 1 did not predict texting at Time 2, supporting the idea that smartphone use leads to greater relationship dissatisfaction rather than the other way around (represented by Path 3 in Figure 2; See Table 1). Roberts and David (2016) also showed in an online study that being snubbed in favor of a phone ("phubbed”) was associated with increased relationship conflict, and in turn, decreased relationship satisfaction, particularly among those with an anxious attachment style. Although cross-sectional in nature, this study provides preliminary evidence that using a smartphone in a partner's presence can disrupt relationship functioning by introducing conflict; furthermore, this increased conflict may reflect the competition that takes place for the attentional resources of one’s partner (supporting Paths 1, 2, and 3 from Figure 2; see Table 1). Several recent studies suggest that the negative effects of phubbing are not restricted to friendships or romantic partners. Roberts and David (2017) recently showed that when bosses phub their employees, the employees’ feelings of trust are undermined, and McDaniel and Radesky (2018) recently showed that parents’ self-reported problematic media use predicted both internalizing and externalizing problematic behavior in their children. This provides further support for the idea that people feel a near universal need to respond to others online in the modern digital age, across multiple contexts. Furthermore, across these contexts, people find phubbing and technoference to be aversive, representing a near-constant competition for an interaction partner's attentional resources. 
In an extension of work on phubbing, Chotpitayasunondh and Douglas (2016) showed in an online study that self-reported “smartphone addiction” (operationalized as a score of 31 or higher for men and 33 or higher for women on the short version of the smartphone addiction scale) was associated with increased perpetration of phubbing, which in turn was associated with phubbing being perceived as more normative. In addition, people who reported phubbing others were also more likely to report being phubbed themselves, suggesting that phubbing is bidirectional in nature, facilitating its perception as a normative behavior (Chotpitayasunondh \& Douglas, 2016). These findings may reflect the idea that many people experience the responsiveness draw that their smartphones create, and although phubbing negatively influences relationship satisfaction, people cannot help but engage with their mobile devices while in the presence of others.

Social networking, relationship satisfaction, and well-being. One area of research that predates the widespread adoption of the smartphone is work that investigated the effects of social networking sites on well-being. Although SNS were initially intended to serve as tools for expanding one's supportive network, providing a convenient way to keep in touch with others, it is important to bear in mind that SNS began at a time when one was required to be in front of a desktop or laptop computer in order to use it (i.e., not while one’s primary activity was interacting with present others). However, as smartphone applications became more advanced and widely used, engaging with SNS frequently (and while in the presence of others) became possible_-and, at least sometimes, problematic. For instance, in a two week experience sampling study in which participants were texted five times per day, Kross and colleagues (2013) found that greater use of Facebook between text messages (with an average time between daily text messages of 168 minutes) led to decreases in affective well-being; furthermore, even after 
controlling for baseline levels of life satisfaction, greater Facebook use during the two week study time period was associated greater decreases in life satisfaction over time (supporting Path 4 from Figure 2; See Table 1). Kross and colleagues (2013) also tested the possibility that when people felt worse, they engaged in Facebook use more frequently, however, there was no evidence for this alternative explanation. Hu, Kim, Siwek, and Wilder (2017) similarly found that greater Facebook use was indirectly linked to decreases in life satisfaction via decreased offline social relationship satisfaction, supporting Paths 2, 4, and 5 from Figure 2; however, greater Facebook use positively predicted enhanced well-being via online social relationship satisfaction. It is crucial to note that to the extent that Facebook advances one's need to foster quality social relationships (e.g., by providing a means to self-disclose and perceive responsiveness), its use can positively affect well-being; however, to the extent that Facebook use detracts from offline relationships (or relationships that are primarily fostered in person), its use can negatively affect psychological well-being.

Despite the negative consequences of technoference, and people's negative emotional reactions to technoference, people engage in it frequently. A recent poll of 3,042 cell phone users (Pew Research Center, 2015) showed that 89\% of adults reported using their smartphones at the last social gathering they attended, yet $82 \%$ of those adults also reported that smartphone use frequently or occasionally detracts from conversations at social gatherings. Interestingly, only $25 \%$ of the 3,042 adults reported that their own smartphone use takes away their attention from others during a social gathering (Pew Research Center, 2015), consistent with the idea that people believe their own divided attention does not negatively affect their ability to perform on their primary task of interest (i.e., driving a car, having a conversation, studying, etc.). 
In summary, literature reviewed here examined how technology can disrupt basic cognitive functioning, as well as how technology can interfere with relationship processes, and in turn, well-being. We proposed a model for how this process unfolds (see Figure 2), and provided evidence for each theoretical link between smartphone use/SNS and disruptions in cognitive and relationship functioning. The findings outlined above are summarized in Table 1, which displays the evidence that supports each path from Figure 2. Collectively, these findings support the idea that people are drawn to use their smartphones even in the presence of others, and that this behavior disrupts cognitive functioning (i.e., reduces attentional resources), is associated with disruptions in relationships processes, and finally, is associated with diminished well-being outcomes.

INSERT TABLE 1 ABOUT HERE

\section{Deeper into Technoference: A Research Agenda}

Following the model proposed by Li et al. (2017) and as outlined in Figure 1, the primary goal of this paper was to make the case for a potential evolutionary mismatch between the ways in which smartphones (and their affordances - access to social networks, texting, etc.) activate the basic intimacy processes required for forming and maintaining high-quality close relationships. As noted above, evolutionary mismatches are defined as situations in which human adaptations that emerged to foster survival in ancestral environments become maladaptive in novel contexts that may differentially cue the same adaptations, or evolved psychological mechanisms (Brenner et al., 2015; Li et al. 2017; Maner \& Kenrick, 2010). Within this 
framework, the modern environment cues ancestral adaptations that essentially "misfire” and may not provide for the same type of adaptive benefits. We have provided credible evidence that humans’ adaptive desires to self-disclose and respond to others, which serve to promote and maintain social bonding, may be at odds with the technological advances that put the entirety of our social network at our fingertips. This final section of the paper outlines a series of initial research questions that, when addressed, will deepen and refine the understanding of these processes and the accuracy of the mismatch framework we outlined above. We have organized this agenda into a series of short questions, all of which can be implemented in a variety of different ways.

\section{Is an evolutionary framing necessary for making the case that cell phone use can} interfere with in-person interactions? The central goal of this paper is to provide an overarching framework for asking and answering questions about why smartphones have the potential to disrupt relationship functioning. Strictly speaking, a mismatch framework is not needed to observe evidence of technoference, and with only a few exceptions, the technoference literature does not rely on an evolutionary framework. We have argued, however, that the field needs theoretical framing to understand the behaviors that may drive technoference, and we believe the evolutionary framing is useful for understanding why smartphones and their affordances exert such a strong pull on our attention. A big part of this analysis is to go beyond the cognitive interference literature to examine not only why these devices are so ubiquitous, but also why they capture our attention so completely. We view this evolutionary framework as very useful in working toward answering these “why?” questions.

\section{Developing testable evolutionary hypotheses regarding self-disclosure and}

responsiveness. A key element for establishing the evolutionary mismatch outline rests in 
identifying behavioral adaptations that operated to confer fitness advantages in the Environment of Evolutionary Adaptiveness (EEA; Buss, 1995), then deriving specific hypotheses from middle-level evolutionary theories about how these adaptations operate (Lewis et al., 2017). We reviewed research indicating that attachment theory is also a middle-level evolutionary theory (see Simpson and Belsky, 2016), and this perspective has proven highly useful in generating testable hypotheses about how people-from the cradle to the grave — think and behave in and around close relationships (e.g., Brumbaugh \& Fraley, 2006). Attachment theory also has a normative component, which refers to the bond itself-the question of what it means to be attached to another person (see Hazan, Gur-Yaish, \& Campa, 2004). As an evolved “commitment device,” for example, romantic love can be understood as an emergent (emotional) property of an attachment bond (Fletcher et al., 2015), but much remains to be learned about the specific behaviors that facilitate social bonding-from close friendships, to pair-bonds, to attachment relationships.

To the extent that self-disclosure and responsiveness are critical to the creation and maintenance of intimate social bonds, what specific evolutionary hypotheses can be derived from an evolutionary perspective on attachment theory? In this context, we are not concerned with the role of technology and relationships per se; rather, specific hypotheses from middle-level evolutionary theories provide a basis for accepting that specific behaviors have adaptive value for the species (Lewis et al., 2017). One straightforward hypothesis is that in new friendships or new romantic relationships, partners’ willingness to disclose intimate personal information and the degree of perceived responsiveness to these disclosures should be associated with the emergence of relationship commitment, trust, and, the development of an attachment bond. We are aware of no studies that have tested the prospective nature of these predictions-for example, 
diary studies in newly formed relationships that examine the ways in which self-disclosure and responsiveness give rise to the specific behaviors that characterize close relationships. Similarly, we would predict that in lab-based paradigms that manipulate self-disclosure and responsiveness in groups (e.g., see Aron, Melinat, Aron, Vallone, \& Bator, 1997; Welker, Baker, Padilla, Holmes, Aron, \& Slatcher, 2014; Birnbaum \& Reis, 2012; Caprariello \& Reis, 2011), greater cooperation would follow. Importantly, these hypotheses and study ideas are derived from the observation that the behaviors subserving intimacy had adaptive value in promoting trust, cooperation, and social bonding. Evidence to this end would advance not only the case for the specific mismatch described here, but also the normative understanding of adult attachment relationships and social bonding in general.

What evidence would support a mismatch? Using legal evidentiary standards of proof around the "case for an evolutionary mismatch" may prove informative (Kagehiro \& Stanton, 1985). Presently, credible evidence exists for the mismatch, but much more data is needed to ultimately make conclusions "beyond a reasonable doubt” and/or to make public health statements of concern. Moreover, any statements about the potential negative consequences of the mismatch must be balanced by an appreciation for the positive contributions of smartphones not only to communication and productivity, but to close relationships as well (e.g., enhancing long-distance relationships, etc.). These positive contributions may operate hand-in-hand with the mismatch, and we simply need more and better science to understand the scope of the potential problem. Central to the case for a mismatch is the idea that because smartphones and their affordances create a responsiveness draw into their virtual world, intimacy in immediate close relationships becomes diminished. Here we suggest harmonizing current intimacy studies with data collected prior to the widespread adoption of smartphones and the emergence of 
application (app)-based SNS involvement on smartphones. The Facebook mobile app was released in 2007, and a number of older intimacy studies (Laurenceau, et al., 1998; Laurenceau, Barrett, \& Rovine, 2005; Reis \& Franks, 1994) could be replicated or re-envisioned for benchmarking against current studies using the same measurement resolution or basic measure set. In this sense, the idea of benchmarking is key: Do people experience less intimacy in their current relationships than they did 10 or 20 years ago? Further, do people feel intimate and close with those with whom they are interacting online? To what extent does online context (e.g., public vs. private SNS posts vs. texting) matter in how close people feel to others online? Evidence that people feel less close and intimate to those with whom they are interacting online compared to face-to-face interactions, and that there are meaningful differences in self-reported intimacy in modern close relationships (i.e., in intimate networks) compared to the intimacy levels reported in the era that immediately preceded the introduction of the smart phone would provide support for the case of mismatch, but it would be far from conclusive. Answers to several other questions can help evaluate the evidence for the case, beginning with the direct link between technoference and perceived partner responsiveness.

\section{Does smartphone use and/or technoference alter perceived partner responsiveness}

(PPR)? Although diminished intimacy over time and in online social interactions provides evidence that points to a potential mismatch, there seem to be many ways in which this data would be limited as well. How do we truly know whether smartphones are the causal agent for the change? What constitutes a "meaningful difference" in diminished intimacy? We believe compelling evidence for a mismatch would emerge from studies that link technology use to diminished PPR on a daily basis. The available evidence indicates that perceptions of the extent to which technology interferes with a relationship is associated with conflict and, in turn, 
diminished relationship quality. Recall that partner responsiveness is critical to interpersonal intimacy. We may ask, then, whether decreased responsiveness, in addition to conflict, explains the association between dyadic smartphone use and relationship quality, and in turn, reductions in personal well-being outcomes (see Figure 3).

It is plausible that a two-step process operates in which smartphone use diminishes partner responsiveness, which creates conflict, and in turn, diminished relationship quality. We are aware of no studies, however, that have ruled out the effects from low PPR or relationship quality to increased smartphone use. In this way, technoference may be the outcome rather than the driver of low relationship quality (cf. Halpern \& Katz, 2017). A dyadic diary study modeled on Figure 3 would be an excellent contribution to the literature. Within this framework, questions about conflict around technology use are important as well. Does conflict follow from diminished PPR, or does conflict lead to diminished PPR? Without conflict around technology use, do we observe diminished PPR? Furthermore, a series of questions may be asked about the health consequences of technoference and whether divorce rates would be influenced by technoference. We believe this work should be done in large, population-level studies (e.g., through Gallup surveys and reports, or embedded into representative longitudinal studies), using pre-registered analyses, in order to gain a clear sense of the scope and consequences of technoference. Minimally, any work in this area must assess three dimensions: (a) conflict surrounding technology in relationships; (b) intimacy processes, and (c) mental or physical health-relevant outcomes.

Is the smartphone a unique form of distraction? Does uncertainty (about interaction partners) matter? As reviewed above, reasonably strong evidence indicates that smartphones 
can disrupt basic cognitive processes that we have argued are essential for maintaining intimate relationships. We have no data, however, to help us understand whether smartphones are simply another powerful means of distraction in relationships (through which we are compelled into virtual worlds largely as a function of the adaptive desires to self-disclose and be responsive), or whether technoference arises when one person is uncertain about the nature of his or her partner's interaction on the smartphone. Of course, there are situations in which we know our partners are playing a solo game, but most smartphone use is social in nature-people are texting others, revealing about the self, and responding to others. At this stage, we do not know enough about technoference to conclude if it emerges as a function of how relationships become degraded in real-time through diminished attention, or if the uniquely social affordances of smartphones simply create new contexts in which people perhaps feel rejected in their relationship. We need research studies that conduct specific tests of these different hypotheses.

Can we be intimate with the entirety of our social network? We have argued that the intimacy processes of self-disclosure and responsiveness are evolutionary adaptations for forming and maintaining small and intimate social networks, which were central to humans’ survival as a species. The idea that smartphones and SNS may activate or take advantage of these adaptations to pull us out of our in-person relationships and thus create technoference is at the heart of the mismatch. To date, however, much of the literature on relationships and technology is framed from a slightly different perspective: Are virtual interactions as good as in-person interactions? This question assumes that in-person interactions provide for "high fidelity" intimacy by virtue of eye contact, smell, touch, and physiological attunement, all of which emerged to service social connection over the course of evolutionary history. Our position is that deep, meaningful, and intimate relationships can be formed and maintained online, but consistent 
with the anthropological literature on network size, we also hypothesize that people cannot maintain intimacy with the entirety of their social network, and the degree to which people make attempts to do so should be directly proportional to diminished quality in immediate kin networks. In other words, to the extent that one has limited resources (e.g., time, attention, energy), we would expect that as one expends those resources on more and more people (via social networking and virtual interactions), the "amount” of intimacy that can be maintained with any one person will be reduced. However, one could also argue that "intimacy" is not a limited resource, and people may indeed be able to maintain an acceptable degree of intimacy with their entire social network. From the perspective of evaluating a potential mismatch, the question of whether virtual relationships are "as good as" in-person interactions is best recast as what are the potential costs (and/or gains) for attempting to maintain intimacy with the entirety of one's social network?

Who is most susceptible to technoference? Our analysis of smartphone use and diminished PPR focuses largely on mediation, with an effort to explain the specific pathways through which heavy smartphone use may undermine relationship satisfaction. However, the question of moderation is relevant as well. Is the proposed association between heavy technology use and reduced PPR less strong for emerging adults who are embedded in a social context of near-constant engagement with one's smartphone? Does attachment style moderate the association between PPR and relationship quality, perhaps with the relationship being stronger for more anxious people who are hyper-vigilant to cues of potential rejection? It is possible that what we have proposed as a normative process only appears or operates when individual differences are taken into account. Determining which individual differences are most relevant is an important task for future research. 


\section{What experimental work would most strongly support the evolutionary mismatch}

framework? From basic laboratory studies to interventions that attempt to reduce technoference, experimental work will prove highly valuable in the future. As highlighted in Table 1, few experimental studies examined whether manipulating how people interact with their smartphone causes changes in relationship quality. Most immediately, laboratory studies are needed to outline the boundaries of technoference-e.g., does partner smartphone use vs. distraction via a book or a magazine diminish PPR, increase conflict, impede self-regulation, or alter attentional capacity? Can these effects be reversed if partners are instructed in different approaches for maintaining PPR? To the extent that the "mere presence” finding replicates in larger samples, what specific psychological processes explain the experimental effects? Although we have theorized that the mere presence of a smartphone represents a competitor for a partner's attentional resources, empirical studies are required to test this theory, and understanding this process better would inform a more general understanding of the mismatch.

Smartphones are here to stay, at least until they are replaced with a superior technology. If technoference is as large a problem as the current evidence suggests, then the emergence of experimental intervention research will be a timely addition to the science in this area as well. Are there specific "harm reduction" strategies that can be implemented around how people interact with their phones that will reduce conflict or maintain in-person responsiveness? For example, do strategies such as setting daily intentions to be "more present in my relationships" make any appreciable difference to partners’ reports of technology use, partner responsiveness, and/or technoference? Scientifically, are there best practices for using your phone that can improve mental health and relationship quality?

\section{Conclusion}


This paper outlines the case for a potential evolutionary mismatch between basic intimacy processes and smartphones. We argued that self-disclosure and responsiveness, interpersonal behaviors that subserve intimacy and promote cooperation, trust, and social bonding, are behavioral adaptations that emerged over the course of evolutionary history to ensure humans' survival by promoting inclusive and reproductive fitness. This analysis examined the ancestral (social) contexts that cued intimacy processes, and we highlighted a growing body of work indicating that intimacy processes are associated with a number of important health advantages. We also argued that the global rise of smartphones, and especially affordances that allow for virtual social connection via texting and social networking sites, create a strong pull for self-disclosure and responsiveness online. At any given moment, smartphones compel people to engage in self-disclosure and responsiveness behaviors with the farthest reaches of their social networks; most simply, the same adaptations for building social bonds in immediate kin networks are engaged in a manner that draws us away from real-time social interactions and into the virtual world. The act of engaging in the virtual world when present with close others is not consequence-free, and this paper summarized a growing literature on the ways in which smartphones may interfere with in-person social connection, including the rise of technoference, defined as relational conflict following technology use.

Despite the emerging science on technoference, the evidence in this area is far from definitive, and our analysis concluded with a series of empirical research questions that we hope will spur advances and a deeper understanding of the core issues surrounding the case for a potential mismatch. As we indicated in the opening of the paper, it would be naïve to conclude smartphones and their affordances are simply good or bad; however, it would be equally naïve to suggest that the rate of technological advancement has no consequences for the ways in which 
humans interact. The key question, then, is whether and how these changes can undermine human health and well-being. The mismatch framework provides an explanation for how this might happen and offers a series of testable research questions that can advance the long-term understanding of technology, relationships, and health. 


\section{References}

Aagaard, J. (2016). Mobile devices, interaction, and distraction: a qualitative exploration of absent presence. Artifical Intelligence and Society, 31(2), 223-231. doi:10.1007/s00146015-0638-z

Aron, A., Melinat, E., Aron, E. N., Vallone, R. D., \& Bator, R. J. (1997). The experimental generation of interpersonal closeness: A procedure and some preliminary findings. Personality and Social Psychology Bulletin, 23(4), 363-377.

Ainsworth, M., Blehar, M., Waters, E., \& Wall, S. (1978). Patterns of attachment: A psychological study of the strange situation. Hillsdale, NJ: Erlbaum.

Alter, A. (2018). Irresistible: The rise of addictive technology and the business of keeping us hooked: Penguin.

Altman, I., \& Taylor, D. A. (1973). Social penetration: The development of interpersonal relationships.

Aron, A., Aron, E. N., \& Smollan, D. (1992). Inclusion of other in the self and the structure of interpersonal closeness. Journal of Personality \& Social Psychology, 63, 596-612.

Aron, A., Melinat, E., Aron, E. N., Vallone, R., \& Bator, R. (1997). The experimental generation of interpersonal closeness: A procedure and some preliminary findings. Personality and Social Psychology Bulletin, 23, 363.

Bahrami, B., Olsen, K., Latham, R. E., Roepstorff, A., Rees, G., \& Frith, C. D. (2010). Optimally interacting minds. Science, 329, 1081-1085.

Bailenson, J. (2018). Experience on demand: How virtual reality is, how it works, and what it can do. New York: W. W. Norton \& Company. 
Baumeister, R. F., \& Leary, M. R. (1995). The need to belong: Desire for interpersonal attachments as a fundamental human motivation. Psychological Bulletin, 117, 497-529.

Bayer, J. B., Campbell, S. W., \& Ling, R. (2015). Connection cues: Activating the norms and habits of social connectedness. Communication Theory, 26(2), 128-149. doi:10.1111/comt.12090

Birnbaum, G. E., \& Reis, H. T. (2012). When does responsiveness pique sexual interest? Attachment and sexual desire in initial acquaintanceships. Personality and Social Psychology Bulletin, 38(7), 946-958.

Bowlby, J. (1969). Attachment and loss: Vol. 1. Attachment. New York: Basic Books.

Bowlby, J. (1988). A secure base: Clinical applications of attachment theory. London: Routledge.

Brenner, S. L., Jones, J. P., Rutanen-Whaley, R. H., Parker, W., Flinn, M. V., \& Muehlenbein, M. P. (2015). Evolutionary mismatch and chronic psychological stress. Journal of Evolutionary Medicine, 30, 32-44.

Brumbaugh, C. C., \& Fraley, R. C. (2006). The evolution of attachment in romantic relationships. Dynamics of romantic love: Attachment, caregiving, and sex, ed. $M$. Mikulincer \& GS Goodman, 71-101.

Buss, D. M. (1995). Evolutionary psychology: A new paradigm for psychological science. Psychological Inquiry, 6(1), 130. http://dx.doi.org/10.1207/s15327965pli0601_1

Campbell, S. W. (2015). Mobile communication and network privatism: A literature review of the implications for diverse, weak, and new ties. Review of Communication Research, 3(1), 1-21. doi: 10.12840/issn.2255-4165.2015.03.01.006 
Caprariello, P. A., \& Reis, H. T. (2011). Perceived partner responsiveness minimizes defensive reactions to failure. Social Psychological and Personality Science, 2(4), 365-372.

Carr, N. (2011). The shallows: What the internet is doing to our brains: WW Norton \& Company.

Chelune, G. J., Robison, J. T., \& Kommor, M. J. (1984). A cognitive interactional model of intimate relationships. Communication, intimacy, and close relationships, 11-40.

Chotpitayasunondh, V., \& Douglas, K. M. (2016). How “phubbing” becomes the norm: The antecedents and consequences of snubbing via smartphone. Computers in Human Behavior, 63, 9-18.

Collins, N. L., \& Miller, L. C. (1994). Self-disclosure and liking: A meta-analytic review. Psychological Bulletin, 116, 457-475.

Consolvo, S., McDonald, D., Toscos, T., Chen, M., Froehlich, J., Harrison, B., Klasnja, P., LaMarca, A., LeGrand, L., Libby, R., Smith, I., \& Landay, J. "Activity Sensing in the Wild: A Field Trial of Ubifit Garden”, in Proc. of the 26th SIGCHI Conference on Human Factors in Computing Systems, 1797-1806, Florence, Italy, April 5-10, 2008.

Csibra, G., \& Gergely, G. (2011). Natural pedagogy as evolutionary adaptation. Philosophical Transactions of the Royal Society B: Biological Sciences, 366, 1149-1157.

Debrot, A., Cook, W. L., Perrez, M., \& Horn, A. B. (2012). Deeds matter: Daily enacted responsiveness and intimacy in couples' daily lives. Journal of Family Psychology, 26, 617.

Derlega, V. J., Metts, S., Petronio, S., \& Margulis, S. T. (1993). Self-disclosure. Sage series on close relationships. Thousand Oaks, CA, US: Sage Publications, Inc. 
Dew, J., \& Tulane, S. (2015). The association between time spent using entertainment media and marital quality in a contemporary dyadic national sample. Journal of Family and Economic Issues, 36(4), 621-632. doi:10.1007/s10834-014-9427-y

Diener, E., \& Seligman, M. E. P. (2002). Very happy people. Psychological Science, 13, 81-84. doi: $10.1111 / 1467-9280.00415$

Dunbar, R. I. M. (2003). The social brain: Mind, language, and society in evolutionary perspective. Annual Review of Anthropology, 32, 163-181. doi: 10.1146/annurev.anthro.32.061002.093158

Dunbar, R. I. M., \& et al. (2015). The structure of online social networks mirrors those in the offline world. Soc. Netw., 43, 39-47.

Dunbar, R. I. M., Marriott, A., \& Duncan, N. D. C. (1997). Human conversational behavior. Human Nature, 8, 231-246. doi: 10.1007/BF02912493

Eisenberger, N. I., Master, S. L., Inagaki, T. K., Taylor, S. E., Shirinyan, D., Lieberman, M. D., \& Naliboff, B. D. (2011). Attachment figures activate a safety signal-related neural region and reduce pain experience. Proceedings of the National Academy of Sciences of the United States of America, 108, 11721-11726. doi: 10.1073/pnas.1108239108

Emler, N. (1990). A social psychology of reputation. European Review of Social Psychology, 1, 171-193.

Emler, N. (1994). Gossip, reputation, and social adaptation. In GoodmanR \& A. Ben Ze'ev (Eds.), Good gossip (pp. 117-133).

Fletcher, G. J. O., Simpson, J. A., Campbell, L., \& Overall, N. C. (2015). Pair-bonding, romantic love, and evolution: The curious case of homo sapiens. Perspectives on Psychological Science, 10, 20-36. 
Frattaroli, J. (2006). Experimental disclosure and its moderators: A meta-analysis. Psychological Bulletin, 132, 823-865.

Gamble, C. (1998). Palaeolithic society and the release from proximity: A network approach to intimate relations. World archaeology, 29, 426-449.

Gardner, W. L., Pickett, C. L., \& Knowles, M. (2005). Social snacking and shielding. The social outcast: Ostracism, social exclusion, rejection, and bullying, 227-242.

Gefen, D., \& Ridings, C. M. (2002). Implementation team responsiveness and user evaluation of customer relationship management: A quasi-experimental design study of social exchange theory. Journal of management information systems, 19(1), 47-69.

Gergen, K. J. (2002). The challenge of absent presence. In Katz, J. E., Aakhus, M. (Eds.), Perpetual contact: Mobile communication, private talk, public performance (pp. 227-241). Cambridge, MA: Cambridge University Press.

Greene, K., Derlega, V. J., \& Mathews, A. (2006). Self-disclosure in personal relationships. In A. L. Vangelisti \& D. Perlman (Eds.), The cambridge handbook of personal pelationships (pp. 409-427). New York, NY: Cambridge University Press.

Guernsey, L. (2014). Garbled in translation: Getting media research to the press and public. Journal of Children and Media, 8, 87-94. doi: 10.1080/17482798.2014.863486

Gunnar, M., \& Quevedo, K. (2007). The neurobiology of stress and development. Annual Review of Psychology, 58, 145-173. doi: 10.1146/annurev.psych.58.110405.085605

Halpern, D., \& Katz, J. E. (2017). Texting's consequences for romantic relationships: A crosslagged analysis highlights its risks. Computers in Human Behavior, 71, 386-394. doi:10.1016/j.chb.2017.01.051 
Hazan, C., \& Shaver, P. R. (1987). Romantic love conceptualized as an attachment process. Journal of Personality and Social Psychology, 52, 511-524. doi: 10.1037/00223514.52.3.511

Hazan, C., Gur-Yaish, N., \& Campa, M. (2004). What does it mean to be attached? In W. S. Rholes \& J. A. Simpson (Eds.), Adult Attachment: New Directions and Emerging Issues (pp. 55-85). New York: Guilford Press.

Hill, R. A., \& Dunbar, R. I. M. (2003). Social network size in humans. Hum. Nature.

Holt-Lunstad, J., Robles, T. F., \& Sbarra, D. A. (2017). Advancing social connection as a public health priority in the united states. American Psychologist, 72, 517-530. doi: 10.1037/amp000010310.1037/amp0000103.supp (Supplemental)

Holt-Lunstad, J., Smith, T. B., Baker, M., Harris, T., \& Stephenson, D. (2015). Loneliness and social isolation as risk factors for mortality: A meta-analytic review. Perspectives on Psychological Science, 10, 227-237. doi: 10.1177/1745691614568352

Holt-Lunstad, J., Smith, T. B., \& Layton, J. B. (2010). Social relationships and mortality risk: A meta-analytic review. PLoS Medicine, 7, e1000316. doi: doi:10.1371/journal.pmed.1000316

Hu, X., Kim, A., Siwek, N., \& Wilder, D. (2017). The Facebook paradox: Effects of Facebooking on individuals’ social relationships and psychological well-being. Frontiers in Psychology, 8, 87, doi:10.3389/fpsyg.2017.00087

Hyman, I. E., Boss, S. M., Wise, B. M., McKenzie, K. E., \& Caggiano, J. M. (2009). Did you see the unicycling clown? Inattentional blindness while walking and talking on a cell phone. Applied Cognitive Psychology, 24(5), 597-607. doi:10.1002/acp.1638 
Jourard, S. M. (1971). Self-disclosure: An experimental analysis of the transparent self. Oxford, England: John Wiley.

Kagehiro, D. K., \& Stanton, W. C. (1985). Legal vs. Quantified definitions of standards of proof. Law and Human Behavior, 9, 159.

Kane, H. S., Slatcher, R. B., Reynolds, B. M., Repetti, R. L., \& Robles, T. F. (2014). Daily selfdisclosure and sleep in couples. Health Psychology, 33, 813-822.

Kaplan, H., Hill, K., Lancaster, J., \& Hurtado, A. M. (2000). A theory of human life history evolution: Diet, intelligence, and longevity. Evolutionary Anthropology, 9(4), 156-185.

Kelley, H. H., Berscheid, E., Cristensen, A., Harvey, J. H., Huston, T. L., Levinger, G., . . . Peterson, D. R. (1983). Analyzing close relationships. In H. H. Kelley, E. Berscheid, A. Christensen, J. H. Harvey, T. L. Huston, G. Levinger, E. McClintock, L. A. Peplau \& D. R. Peterson (Eds.), Close relationships. (pp. 20-89). New York: W. H. Freeman.

Khan, C. M., Iida, M., Stephens, M. A. P., Fekete, E. M., Druley, J. A., \& Greene, K. A. (2009). Spousal support following knee surgery: Roles of self-efficacy and perceived emotional responsiveness. Rehabilitation Psychology, 54, 28-32.

Kim, J., \& Lee, J.-E. R. (2011). The facebook paths to happiness: Effects of the number of facebook friends and self-presentation on subjective well-being. CyberPsychology, behavior, and social networking, 14, 359-364.

King, A. L. S., Valença, A. M., Silva, A., Baczynski, T., Carvalho, M., \& Nardi, A. E. (2013). Nomophobia: Dependency on virtual environments or social phobia? Computers in Human Behavior, 29, 140-144.

Kluger, A. N., \& Zaidel, K. (2013). Are listeners perceived as leaders? International Journal of Listening, 27, 73-84. 
Kross, E., Verduyn, P., Demiralp, E., Park, J., Lee, D. S., Lin, N., \& et al. (2013). Facebook use predicts declines in subjective well-being in young adults. PLoS One, 8(8), e69841. doi:10.1371/journal.pone.0069841

Lane, N. D., Miluzzo, E., Lu, H., Peebles, D., Choudhury, T., \& Campbell, A. T. (2010). A survey of mobile phone sensing. IEEE Communications magazine, 48(9).

Landis, M. H., \& Burtt, H. E. (1924). A study of conversations. Journal of Compar. Psychology, 4, 81-89.

Larzelere, R. E., \& Huston, T. L. (1980). The dyadic trust scale: Toward understanding interpersonal trust in close relationships. Journal of Marriage and the Family, 595-604.

Laurenceau, J.-P., Barrett, L. F., \& Pietromonaco, P. R. (1998). Intimacy as an interpersonal process: The importance of self-disclosure, partner disclosure, and perceived partner responsiveness in interpersonal exchanges. Journal of Personality and Social Psychology, 74, 1238-1251.

Laurenceau, J.-P., Barrett, L. F., \& Rovine, M. J. (2005). The interpersonal process model of intimacy in marriage: A daily-diary and multilevel modeling approach. Journal of Family Psychology, 19, 314.

Leung, L., \& Lee, P. S. (2005). Multiple determinants of life quality: The roles of internet activities, use of new media, social support, and leisure activities. Telematics and Informatics, 22, 161-180.

Levy, E. C., Rafaeli, S., \& Ariel, Y. (2016). The effect of online interruptions on the quality of cognitive performance. Telematics and Informatics, 33(4), 1014-1021. doi:10.1016/j.tele.2016.03.003 
Lewis, D. M. G., Al-Shawaf, L., Conroy-Beam, D., Asao, K., \& Buss, D. M. (2017). Evolutionary psychology: A how-to guide. American Psychologist, 72(4), 353373. http://dx.doi.org/10.1037/a0040409

Li, N. P., van Vugt, M., \& Colarelli, S. M. (2017). The evolutionary mismatch hypothesis: Implications for psychological science. Current Directions in Psychological Science, 0963721417731378.

Lieberman, M. D. (2013). Social: Why our brains are wired to connect New York: Crown.

Ling, R. (2012). Taken for grantedness: The embedding of mobile communication into society. Cambridge, Ma: MIT Press.

Luxton, D. D., McCann, R. A., Bush, N. E., Mishkind, M. C., \& Reger, G. M. (2011). mHealth for mental health: Integrating smartphone technology in behavioral healthcare. Professional Psychology: Research and Practice, 42(6), 505.

MacDonald Jr, A. P., Kessel, V. S., \& Fuller, J. B. (1972). Self-disclosure and two kinds of trust. Psychological Reports, 30(1), 143-148.

Machin, A. J., \& Dunbar, R. I. M. (2011). The brain opioid theory of social attachment: A review of the evidence. Behaviour, 148, 985-1025.

Maner, J. K., \& Kenrick, D. T. (2010). When adaptations go awry: Functional and dysfunctional aspects of social anxiety. Social issues and policy review, 4, 111-142.

McDaniel, B. T., \& Coyne, S. M. (2016). “Technoference”: The interference of technology in couple relationships and implications for women's personal and relational well-being. Psychology of Popular Media Culture, 5, 85. 
McDaniel, B. T., Galovan, A. M., Cravens, J. D., \& Drouin, M. (2018). “Technoference” and implications for mothers' and fathers' couple and coparenting relationship quality. Computers in Human Behavior, 80, 303-313.

McDaniel, B. T., \& Radesky, J. S. (2018). Technoference: Parent distraction with technology and associations with child behavior problems. Child development, 89, 100-109.

Meaney, M. J. (2010). Epigenetics and the biological definition of gene x environment interactions. Child Development, 81, 41-79. doi: 10.1111/j.1467-8624.2009.01381.x

Milardo, R. M. (1992). Comparative methods for delineating social networks. Journal of social and personal relationships, 9, 447-461.

Miluzzo, E., Lane, N. D., Fodor, K., Peterson, R., Lu, H., Musolesi, M., ... \& Campbell, A. T. (2008, November). Sensing meets mobile social networks: the design, implementation and evaluation of the cenceme application. In Proceedings of the 6th ACM conference on Embedded network sensor systems (pp. 337-350). ACM.

Misra, S., Cheng, L., Genevie, J., \& Yuan, M. (2014). The iPhone effect. Environment and Behavior, 48(2), 275-298. doi:10.1177/0013916514539755

Morgans, J. (2018). Your addiction to social media is no accident. Retrieved January 29, 2018, from https://www.vice.com/en_us/article/vv5jkb/the-secret-ways-social-media-is-builtfor-addiction

Morrison, C. M., \& Gore, H. (2010). The relationship between excessive internet use and depression: A questionnaire-based study of 1,319 young people and adults. Psychopathology, 43, 121-126. doi: 10.1159/000277001. Document Type: journal DOI: 10.1159/000277001. 
Naaman, M., Boase, J., \& Lai, C.-H. (2010). Is it really about me?: Message content in social awareness streams. Paper presented at the Proceedings of the 2010 ACM conference on Computer supported cooperative work, Savannah, Georgia, USA.

Nabi, R. L., Prestin, A., \& So, J. (2013). Facebook friends with (health) benefits? Exploring social network site use and perceptions of social support, stress, and well-being. Cyberpsychology, Behavior, and Social Networking, 16, 721-727.

Neira, B., Corey, J., \& Barber, B. L. (2014). Social networking site use: Linked to adolescents' social self-concept, self-esteem, and depressed mood. Australian Journal of Psychology, 66, 56-64.

Nowland, R., Necka, E. A., \& Cacioppo, J. T. (2017). Loneliness and social internet use: Pathways to reconnection in a digital world? Perspectives on Psychological Science, 13, $70-87$

Otto, A. K., Laurenceau, J.-P., Siegel, S. D., \& Belcher, A. J. (2015). Capitalizing on everyday positive events uniquely predicts daily intimacy and well-being in couples coping with breast cancer. Journal of Family Psychology, 29, 69.

Pew Research Center. (2014). Couples, the internet, and social media. Retrieved on January 18, 2018 from: http://www.pewinternet.org/2014/02/11/couples-the-internet-and-socialmedia/.

Pew Research Center. (2015). U.S. Smartphone use in 2015. Retired on January 15, 2018 from: http://www.pewinternet.org/2015/04/01/us-smartphone-use-in-2015/.

Pew Research Center. (2016). Smartphne ownership and internet usage continues to climb in emerging economies. Retrieved on January 15, 2017 from: 
http://www.pewglobal.org/2016/02/22/smartphone-ownership-and-internet-usagecontinues-to-climb-in-emerging-economies/

Pew Research Center. (2017). Internet and techonology: Mobile fact sheet. Retrieved January 29, 2018, from: http://www.pewinternet.org/fact-sheet/mobile/

Pew Research Center. (2018a). Social media use in 2018. Retrieved on March 1, 2018 from: http://www.pewinternet.org/2018/03/01/social-media-use-in-2018/.

Pew Research Center. (2018b). The future of well-being in a tech-saturated world. Retrieved on October 30, 2018 from: http://www.pewinternet.org/2018/04/17/the-future-of-well-beingin-a-tech-saturated-world/

Plummer, T. (2004). Flaked stones and old bones: Biological and cultural evolution at the dawn of technology. American journal of physical anthropology, 125, 118-164.

Przybylski, A. K., Murayama, K., DeHaan, C. R., \& Gladwell, V. (2013). Motivational, emotional, and behavioral correlates of fear of missing out. Computers in Human Behavior, 29, 1841-1848.

Przybylski, A. K., \& Weinstein, N. (2013). Can you connect with me now? How the presence of mobile communication technology influences face-to-face conversation quality. Journal of Social and Personal Relationships, 30(3), 237-246, http://dx.doi.org/10.1177/0265407512453827.

Reis, H. T. (2012). Perceived partner responsiveness as an organizing theme for the study of relationships and well-being Interdisciplinary research on close relationships: The case for integration. (pp. 27-52). Washington, DC: American Psychological Association. 
Reis, H. T., Clark, M. S., \& Holmes, J. G. (2004). Perceived partner responsiveness as an organizing construct in the study of intimacy and closeness. In D. J. Mashek \& A. P. Aron (Eds.), Handbook of closeness and intimacy. (pp. 201-225).

Reis, H. T., Clark, M. S., Pereira Gray, D. J., Tsai, F.-F., Brown, J. B., Stewart, M., \& Underwood, L. G. (2008). Measuring responsiveness in the therapeutic relationship: A patient perspective. Basic and Applied Social Psychology, 30, 339-348.

Reis, H. T., \& Franks, P. (1994). The role of intimacy and social support in health outcomes: Two processes or one? Personal Relationships, 1, 185-197.

Reis, H. T., \& Shaver, P. (1988). Intimacy as an interpersonal process. In S. Duck (Ed.), Handbook of personal relationships (pp. 367-389). Chichester, England: Wiley.

Roberts, J. A., \& David, M. E. (2016). My life has become a major distraction from my cell phone: Partner phubbing and relationship satisfaction among romantic partners. Computers in Human Behavior, 54, 134-141.

Roberts, J. A., \& David, M. E. (2017). Put down your phone and listen to me: How boss phubbing undermines the psychological conditions necessary for employee engagement. Computers in Human Behavior, 75, 206-217.

Robles, T. F., Slatcher, R. B., Trombello, J. M., \& McGinn, M. M. (2014). Marital quality and health: A meta-analytic review. Psychological Bulletin, 140, 140-187.

Rotondi, V., Stanca, L., \& Tomasuolo, M. (2017). Connecting alone: Smartphone Use, quality of social interactions and well-being. SSRN Electronic Journal. doi:10.2139/ssrn.2893027

Rowland, M. A., Greenbaum, J. M., \& Deeds, E. J. (2017). Crosstalk and the evolvability of intracellular communication. Nature Communications, 8, 16009. doi:10.1038/ncomms16009 
Sagioglou, C., \& Greitemeyer, T. (2014). Facebook’s emotional consequences: Why facebook causes a decrease in mood and why people still use it. Computers in Human Behavior, 35, 359-363.

Selcuk, E., Stanton, S. C., Slatcher, R. B., \& Ong, A. D. (2017). Perceived partner responsiveness predicts better sleep quality through lower anxiety. Social Psychological and Personality Science, 8, 83-92. doi: 10.1177/1948550616662128

Selcuk, E., Zayas, V., Günaydin, G., Hazan, C., \& Kross, E. (2012). Mental representations of attachment figures facilitate recovery following upsetting autobiographical memory recall. Journal of Personality and Social Psychology, 103, 362-378. doi: 10.1037/a0028125

Selfhout, M. H. W., Branje, S. J. T., Delsing, M., ter Bogt, T. F. M., \& Meeus, W. H. J. (2009). Different types of internet use, depression, and social anxiety: The role of perceived friendship quality. Journal of Adolescence, 32, 819-833. doi:

10.1016/j.adolescence.2008.10.011

Shakya, H. B., \& Christakis, N. A. (2017). Association of facebook use with compromised wellbeing: A longitudinal study. American Journal of Epidemiology, 185, 203-211.

Simpson, J. A., \& Belsky, J. (2016). Attachment theory within a modern evolutionary framework. In J. Cassidy \& P. R. Shaver (Eds.), Handbook of attachment: Theory, research, and clinical applications ( $3^{\text {rd }}$ ed.) (pp. 91-116). New York: Guilford.

Slatcher, R. B., Robles, T. F., Repetti, R., \& Fellows, M. D. (2010). Momentary work worries, marital disclosure and salivary cortisol among parents of young children. Psychosomatic Medicine, 72, 887-896. 
Slatcher, R. B., \& Schoebi, D. (2017). Protective processes underlying the links between marital quality and physical health. Current Opinion in Psychology, 3, 148-152 doi: doi: 10.1016/j.copsyc.2016.09.002

Slatcher, R. B., \& Selcuk, E. (2017). A social psychological perspective on the links between close relationships and health. Current Directions in Psychological Science, 26, 16-21.

Slatcher, R. B., Selcuk, E., \& Ong, A. D. (2015). Perceived partner responsiveness predicts diurnal cortisol profiles 10 years later. Psychological Science, 26, 972-982.

Smyth, J. M., Hockemeyer, J. R., \& Tulloch, H. (2008). Expressive writing and post-traumatic stress disorder: Effects on trauma symptoms, mood states, and cortisol reactivity. [Peer Reviewed]. British Journal of Health Psychology, 13, 85-93. doi:

10.1348/135910707x250866

Spencer, T. A., Lambertsen, A., Hubler, D. S., \& Burr, B. K. (2017). Assessing the mediating effect of relationship dynamics between perceptions of problematic media use and relationship satisfaction. Contemporary Family Therapy, 39(2), 80-86. doi:10.1007/s10591-017-9407-0

Sprecher, S., Hampton, A. J., Heinzel, H. J., \& Felmlee, D. (2016). Can I connect with both you and my social network? Access to network-salient communication technology and getacquainted interactions. Computers in Human Behavior, 62, 423-432.

doi:10.1016/j.chb.2016.03.090

Statista. (2018a). Average daily time spent on social media worldwide 2012-2017. Retrieved January 29, 2018, from https://www.statista.com/statistics/433871/daily-social-mediausage-worldwide/ 
Statista. (2018b). Share of u.S. Social media minutes 2016, by platform. Retrieved January 29, 2018, from https://www.statista.com/statistics/444986/social-content-platform-time-usa/

Stothart, C., Mitchum, A., \& Yehnert, C. (2015). The attentional cost of receiving a cell phone notification. Journal of Experimental Psychology: Human Perception and Performance, 41(4), 893-897. doi:10.1037/xhp0000100

Tamir, D. I., \& Mitchell, J. P. (2012). Disclosing information about the self is intrinsically rewarding. Proceedings of the National Academy of Sciences, 109, 8038-8043.

Tamir, D. I., \& Ward, A. F. (2015). Old desires, new media. In W.Hofmann \& L.Nordgren (Eds.), The psychology of desire (pp. 432-455).

Tasfiliz, D., Selcuk, E., Gunaydin, G., Slatcher, R. B., Corriero, E., \& Ong, A. D. (in press). Patterns of perceived partner responsiveness and well-being in japan and the united states. Journal of Family Psychology.

Thiagarajan, A., Ravindranath, L., LaCurts, K., Madden, S., Balakrishnan, H., Toledo, S., \& Eriksson, J. (2009, November). VTrack: accurate, energy-aware road traffic delay estimation using mobile phones. In Proceedings of the 7th ACM Conference on Embedded Networked Sensor Systems (pp. 85-98). ACM.

Thornton, B., Faires, A., Robbins, M., \& Rollins, E. (2014). The mere presence of a cell phone may be distracting. Social Psychology, 45(6), 479-488. doi:10.1027/1864-9335/a000216

Tobin, E. T., Kane, H. S., Saleh, D. J., Wildman, D. E., Breen, E. C., Secord, E., \& Slatcher, R. B. (2015). Asthma-related immune responses in youth with asthma: Associations with maternal responsiveness and expressions of positive and negative affect in daily life. Psychosomatic Medicine, 77, 892-902. doi: 10.1097/PSY.0000000000000236 
Tomasello, M. (1999). The cultural origins of human cognition. Cambridge, MA: Harvard University Press.

Turkle, S. (2011). Alone together: Why we expect more from technology and less from ourselves: New York: Basic Books.

Twenge, J. (2017). Igen: The 10 trends shaping today’s young people—and the nation: New York: Atria Books.

Valenzuela, S., Park, N., \& Kee, K. F. (2009). Is there social capital in a social network site?: Facebook use and college students' life satisfaction, trust, and participation. Journal of computer-mediated communication, 14, 875-901.

Vanden Abeele, M. M., Antheunis, M. L., \& Schouten, A. P. (2016). The effect of mobile messaging during a conversation on impression formation and interaction quality. Computers in Human Behavior, 62, 562-569. doi:10.1016/j.chb.2016.04.005

Van den Eijnden, R. J., Meerkerk, G.-J., Vermulst, A. A., Spijkerman, R., \& Engels, R. C. (2008). Online communication, compulsive internet use, and psychosocial well-being among adolescents: A longitudinal study. Developmental psychology, 44, 655.

van Middendorp, H. t., Geenen, R., Sorbi, M. J., van Doornen, L. J. P., \& Bijlsma, J. W. J. (2009). Health and physiological effects of an emotional disclosure intervention adapted for application at home: A randomized clinical trial in rheumatoid arthritis. [Peer Reviewed]. Psychotherapy and Psychosomatics, 78, 145-151. doi: 10.1159/000206868

Wallsten, S. (2013). What are we not doing when we're online. (NBER Working Paper No. 19549). Cambridge, MA: National Bureau of Economic Research.

Wang, X., Xie, X., Wang, Y., Wang, P., \& Lei, L. (2017). Partner phubbing and depression among married Chinese adults: The roles of relationship satisfaction and relationship 
length. Personality and Individual Differences, 110, 12-17. doi:10.1016/j.paid.2017.01.014

Ward, A. F. (2013). Supernormal: How the internet is changing our memories and our minds, Psychological Inquiry, 24(4), 341-348. Doi: 10.1080/1047840X.2013.850148

Ward, A. F., Duke, K., Gneezy, A., \& Bos, M. W. (2017). Brain drain: The mere presence of one's own smartphone reduces available cognitive capacity. Journal of the Association for Consumer Research, 2(2), 140-154. doi:10.1086/691462

Weeks, T. L., \& Pasupathi, M. (2011). Stability and change self-integration for negative events: The role of listener responsiveness and elaboration. Journal of personality, 79, 469-498.

Welker, K. M., Baker, L., Padilla, A., Holmes, H., Aron, A., \& Slatcher, R. B. (2014). Effects of self-disclosure and responsiveness between couples on passionate love within couples. Personal Relationships, 21(4), 692-708.

Wilmer, H. H., Sherman, L. E., \& Chein, J. M. (2017). Smartphones and cognition: A review of research exploring the links between mobile technology habits and cognitive functioning. Frontiers in Psychology, 8. doi:10.3389/fpsyg.2017.00605 
Table 1. Summary of key findings on technology and relationships.

\begin{tabular}{|c|c|c|c|}
\hline Pathway & Author(s) & Year & Key Findings \\
\hline Path 1: Smartphone Use & Stothart et al., & 2015 & Phone notifications are associated with poorer performance on the sustained attention to \\
\hline and SNS Disrupt & & & response task (SART). \\
\hline \multirow[t]{4}{*}{ Cognitive Processes } & Thornton et al., & 2014 & Mere presence of smartphones is associated with poorer cognitive performance on trail- \\
\hline & & & making task. \\
\hline & Hyman et al., & 2009 & Only $25 \%$ of people notice a unicycling clown while walking and using their phones. \\
\hline & Ward et al., & 2017 & Mere presence of a smartphone is associated with reduced working memory capacity. \\
\hline Path 2: Disrupted & Aagaard & 2016 & Although there is little empirical evidence for this link, to the extent that attention is \\
\hline Cognitive Processes & & & necessary for relationship processes to unfold (e.g., self-disclosure, responsiveness), the \\
\hline Lead to Disrupted & & & studies illustrating undermined cognitive functioning support this theoretical link. In a \\
\hline \multirow[t]{2}{*}{ Relationship Processes } & & & small qualitative study, participants reported their own phone use as detrimental to their \\
\hline & & & attention, negatively influencing their ability to interact with others. \\
\hline Path 3: Smartphone Use & Przybylski \& Weinstein & 2013 & Mere presence of a phone is associated with reduced relationship satisfaction, especially \\
\hline and SNS Disrupt & & & when the topic of conversation is meaningful. \\
\hline
\end{tabular}

Relationship Processes 
Spencer et al.,

Roberts \& David

Halpern \& Katz

Misra et al.,

McDaniel \& Coyne

McDaniel \& Radesky

Dew \& Tulane
2017 Perceptions of problematic technology use are associated with criticism-defensive and demand-withdraw communication patterns (and in turn, reduced relationship satisfaction).

2016 Partner "phubbing” (phone snubbing) is associated with conflict over technology, and in turn, reductions in relationship satisfaction.

2017 Texting frequency at time 1 significantly predicts decreases in relationship satisfaction one year later (there was no effect of time 1 relationship quality on texting one year later).

2016 The mere presence of a phone is associated with reductions of perceived empathy in a naturalistic setting.

2016 Technology interference is associated with increased conflict over technology, and in turn, reductions in relationship satisfaction.

2018 Self-reported parent technoference is associated with greater internalizing and externalizing behavioral problems in children.

2015 Husbands’ social networking and wives’ online gaming are negatively associated with marital quality; technology use incongruence is associated with increased conflict. 
Roberts \& David

Path 4: Smartphone Use Wang et al., and SNS Lead to

Reduced Well-Being $\quad$ Hu et al.,

Kross et al.,

Rotondi et al.,

Path 5: Disruption of Wang et al.,

Relationship Processes

Leads to Reduced Well- McDaniel \& Coyne

Being
2017 Boss phubbing is linked to undermined employee trust and reductions in employee engagement.

2017 Partner phubbing is directly linked to increases in depression, even when reductions in relationship satisfaction are accounted for.

2017 Facebook use is linked to more negative offline social relationships and decreased psychological well-being (but Facebook use is positively associated with well-being through more satisfying online relationships).

2013 Facebook use is linked to decreased satisfaction with life and reduced subjective wellbeing over a two-week experience sampling study.

2017 Time spent with friends in person is valued less when individuals use smartphones, and smartphone use is linked to reductions in life satisfaction.

2017 Partner phubbing is associated with reductions in relationship satisfaction, which in turn is associated with increases in depression among married Chinese couples.

2016 Conflict over technology use is significantly related to depression among women. 

undermined life satisfaction and increased depression.

Note. Each path number in the table refers to a specific path illustrated in Figure 2. 

A

THE EVOLUTION OF SOCIAL BONDING

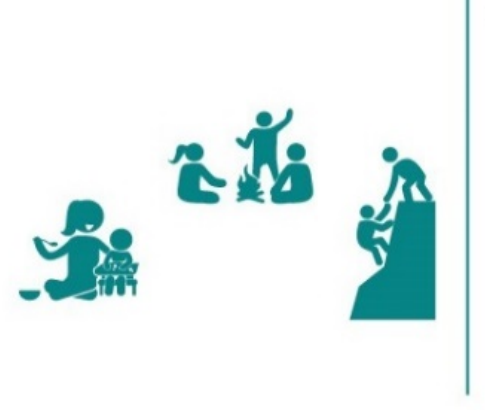

B

\section{EXPRESSIONS OF SELF-DISCLOSURE AND RESPONSIVENESS IN SMALL GROUPS}

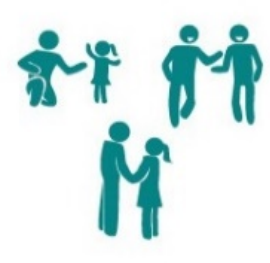

c NEW MEDIUMS FOR
SELF-DISCLOSURE
AND RESPONSIVENESS

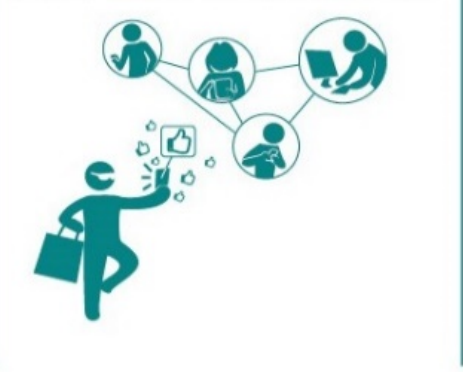

D

THE EMERGENCE OF TECHNOFERENCE

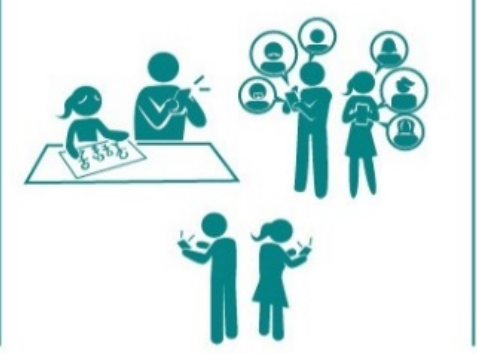

E

THE CONSEQUENCES OF TECHNOFERENCE
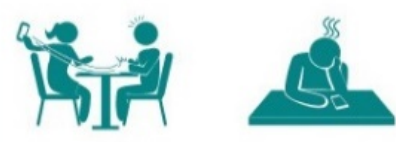

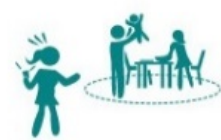

\footnotetext{
Figure 1. The panels in this figure organize the major sections of this paper, beginning with an analysis of the evolution of human attachment as an ancestral adaptation and the ways in which small group contexts pull for or cue the processes of self-disclosure and responsiveness (Panels A \& B). The paper then describes the ways in which smartphones and their affordances provide new mediums for these processes (Panel C), relationship problems that may emerge as a consequence of the mismatch (Panel D), and potential consequences of technoference (Panel E).
} 


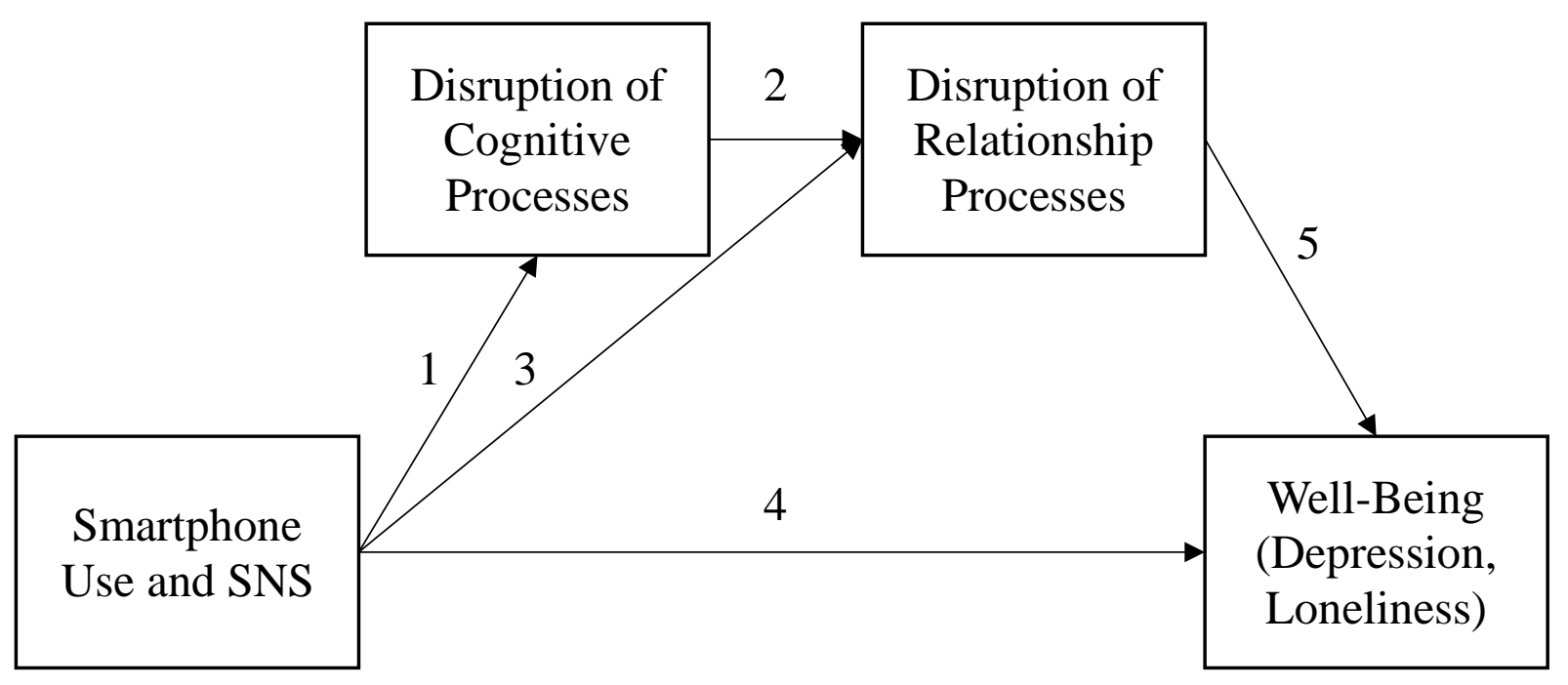

Figure 2. Smartphone use and SNS disrupt cognitive and relationship processes, and lead (both directly and indirectly) to decreases in relationship satisfaction and well-being. The numbered paths correspond to evidence that supports these linkages (summarized in Table 1). 


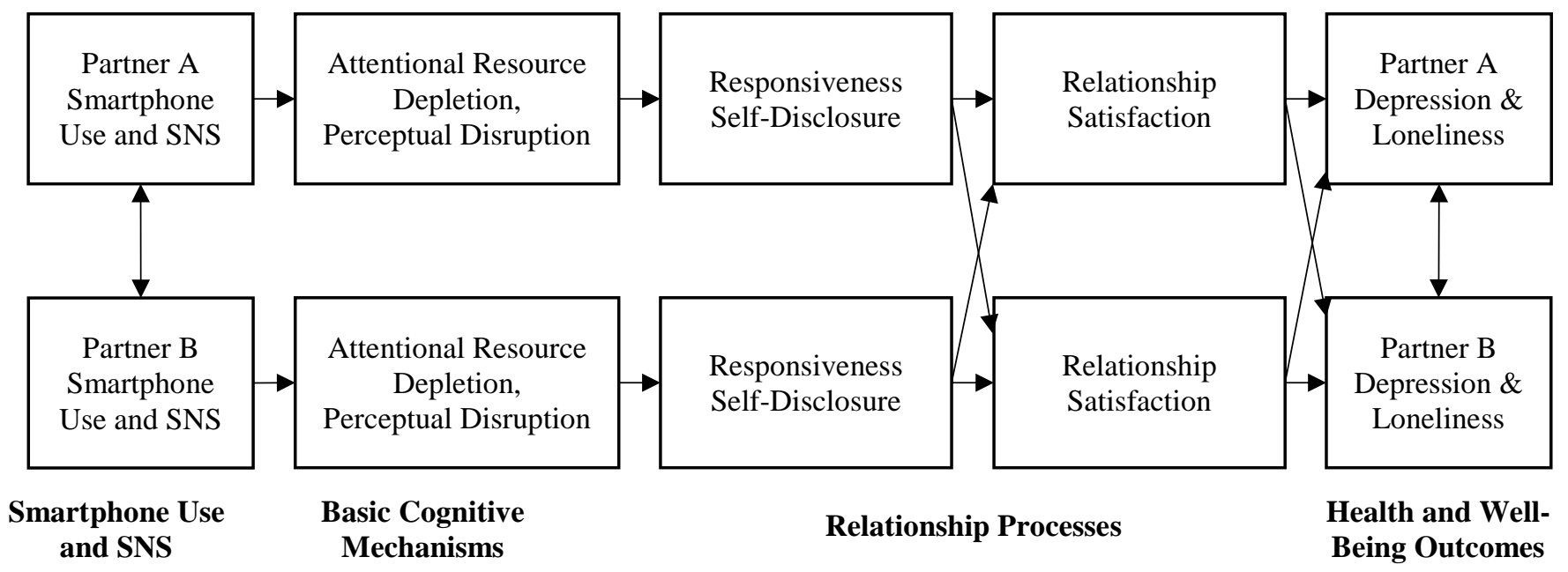

Figure 3. In a dyadic context, smartphone use and SNS disrupt attentional and perceptual processes, which in turn negatively influence relationship processes (e.g., self-disclosure, responsiveness) and relationship quality, which in turn negatively influences well-being. 